\title{
Chemical Aspects of the Candidate Antiferromagnetic Topological Insulator $\mathrm{MnBi}_{2} \mathrm{Te}_{4}$
}

Alexander Zeugner, ${ }^{\dagger}$ Frederik Nietschke, ${ }^{\#}$ Anja U. B. Wolter, ${ }^{\nabla}$ Sebastian Gaß, ${ }^{\nabla}$ Raphael C. Vidal, ${ }^{\circ}$ Thiago R. F. Peixoto, ${ }^{\triangleright}$ Darius Pohl, ${ }^{\ddagger, \nabla}{ }^{\circ}$ Christine Damm, ${ }^{\nabla}$ Axel Lubk, ${ }^{\nabla}$ Richard Hentrich, ${ }^{\nabla}$ Simon K. Moser, ${ }^{\bigcirc}$, Celso Fornari, $^{\bigcirc}$ Chul Hee Min, ${ }^{\bigcirc}$ Sonja Schatz, ${ }^{\bigcirc}$ Katharina Kißner, ${ }^{\circ}$ Maximilian Ünzelmann, ${ }^{\bigcirc}$ Martin Kaiser, ${ }^{\dagger}$ Francesco Scaravaggi, ${ }^{\nabla}$ Bernd Rellinghaus, ${ }^{\perp, \nabla}$ Kornelius Nielsch, ${ }^{\S, \|, \nabla}$ Christian Hess, ${ }^{\nabla}$ Bernd Büchner, ${ }^{\ddagger}, \nabla$ Friedrich Reinert, ${ }^{,}$Hendrik Bentmann, ${ }^{\bigcirc}$

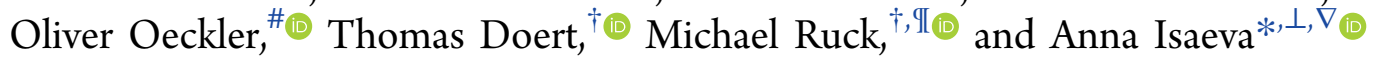

${ }^{\dagger}$ Faculty of Chemistry and Food Chemistry, ${ }^{\ddagger}$ Dresden Center for Nanoanalysis, cfaed, ${ }^{\S}$ Institute of Materials Science, "Institute of Applied Physics, and ${ }^{\perp}$ Institute of Solid State Physics, Technische Universität Dresden, 01062 Dresden, Germany

${ }^{\#}$ Institute for Mineralogy, Crystallography and Materials Science, Leipzig University, 04275 Leipzig, Germany

${ }^{\nabla}$ Leibniz-Institute for Solid State and Materials Research, 01069 Dresden, Germany

OExperimentelle Physik VII, Universität Würzburg, 97074 Würzburg, Germany

Advanced Light Source, Lawrence Berkeley National Laboratory, Berkeley, California 94720, United States

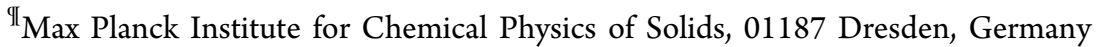

\section{Supporting Information}

ABSTRACT: High-quality single crystals of $\mathrm{MnBi}_{2} \mathrm{Te}_{4}$ are grown for the first time by slow cooling within a narrow range between the melting points of $\mathrm{Bi}_{2} \mathrm{Te}_{3}\left(586{ }^{\circ} \mathrm{C}\right)$ and $\mathrm{MnBi}_{2} \mathrm{Te}_{4}$ $\left(600{ }^{\circ} \mathrm{C}\right)$. Single-crystal $\mathrm{X}$-ray diffraction and electron microscopy reveal ubiquitous antisite defects in both cation sites and, possibly, Mn vacancies $\left(\mathrm{Mn}_{0.85(3)} \mathrm{Bi}_{2.10(3)} \mathrm{Te}_{4}\right)$. Thermochemical studies complemented with high-temperature X-ray diffraction establish a limited hightemperature range of phase stability and metastability at room temperature. Nevertheless, the synthesis of $\mathrm{MnBi}_{2} \mathrm{Te}_{4}$ can be scaled-up as powders can be obtained at subsolidus temperatures and quenched at room temperature. Bulk samples exhibit long-range antiferromagnetic ordering below $24 \mathrm{~K}$. The $\mathrm{Mn}$ (II) out-of-plane magnetic state is confirmed by the magnetization, X-ray photoemission, $\mathrm{X}$-ray absorption, and linear dichroism measurements. The compound shows a metallic type of resistivity in the range $4.5-300 \mathrm{~K}$ and is an n-type conductor that reaches a

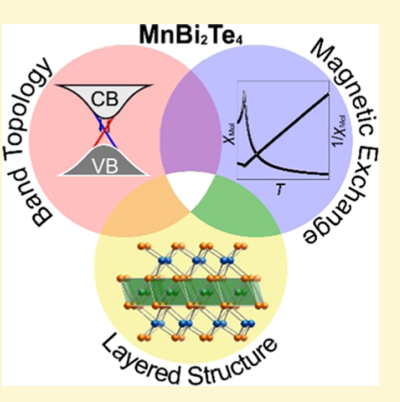
thermoelectric figure of merit up to $Z T=0.17$. Angle-resolved photoemission experiments show a surface state forming a gapped Dirac cone, thus strengthening $\mathrm{MnBi}_{2} \mathrm{Te}_{4}$ as a promising candidate for the intrinsic magnetic topological insulator, in accordance with theoretical predictions. The developed synthetic protocols enable further experimental studies of a crossover between magnetic ordering and nontrivial topology in bulk $\mathrm{MnBi}_{2} \mathrm{Te}_{4}$.

\section{INTRODUCTION}

A sizeable portion of the present research on topological materials ${ }^{1}$ is conducted in pursuit of candidate materials for the quantum anomalous Hall effect (QAHE) $)^{2,3}$ and the topological magnetoelectric effect. ${ }^{4}$ One of the most compelling prospects of topological phases is the manifestation of quantum effects under ambient conditions. A magnetic topological insulator (TI) with large spin-orbit coupling could exhibit quantized resistance and, concurrently, one nondissipative spin-polarized channel along the edges at room temperature without an external magnetic field. ${ }^{5}$

The QAHE was realized first in 2013 in a thin film of the Crand $\mathrm{Bi}$-doped topological insulator $\mathrm{Sb}_{2-x} \mathrm{Te}_{3}$ in the millikelvin range. ${ }^{6}$ Moreover, high external magnetic fields above $10 \mathrm{~T}$ were required to suppress the longitudinal resistance (dissipative conduction channels). ${ }^{6}$ V-doped samples ${ }^{7}$ showed superior properties compared to $\mathrm{Cr}$, but, nevertheless, the signatures of the QAH state vanished above $\sim 5 \mathrm{~K}$. Promising results have been obtained for magnetically modulation-doped topological insulators, where the QAHE stabilizes up to $1-2$ $\mathrm{K}^{8-10}$ Alternative QAHE proposals are based on the proximity effect, i.e., on the direct coupling via a shared interface between a bulk (anti)ferromagnet and a TI. ${ }^{11-17}$ Theory has demonstrated some disadvantages of this approach ${ }^{18}$ and has introduced a new principle coined "magnetic extension". ${ }^{19,20}$ According to this concept, the structural similarity between a magnetically ordered overlay and a TI substrate promotes better overlap between their states, in particular, in layered

Received: December 3, 2018

Revised: $\quad$ March 20, 2019

Published: April 2, 2019 

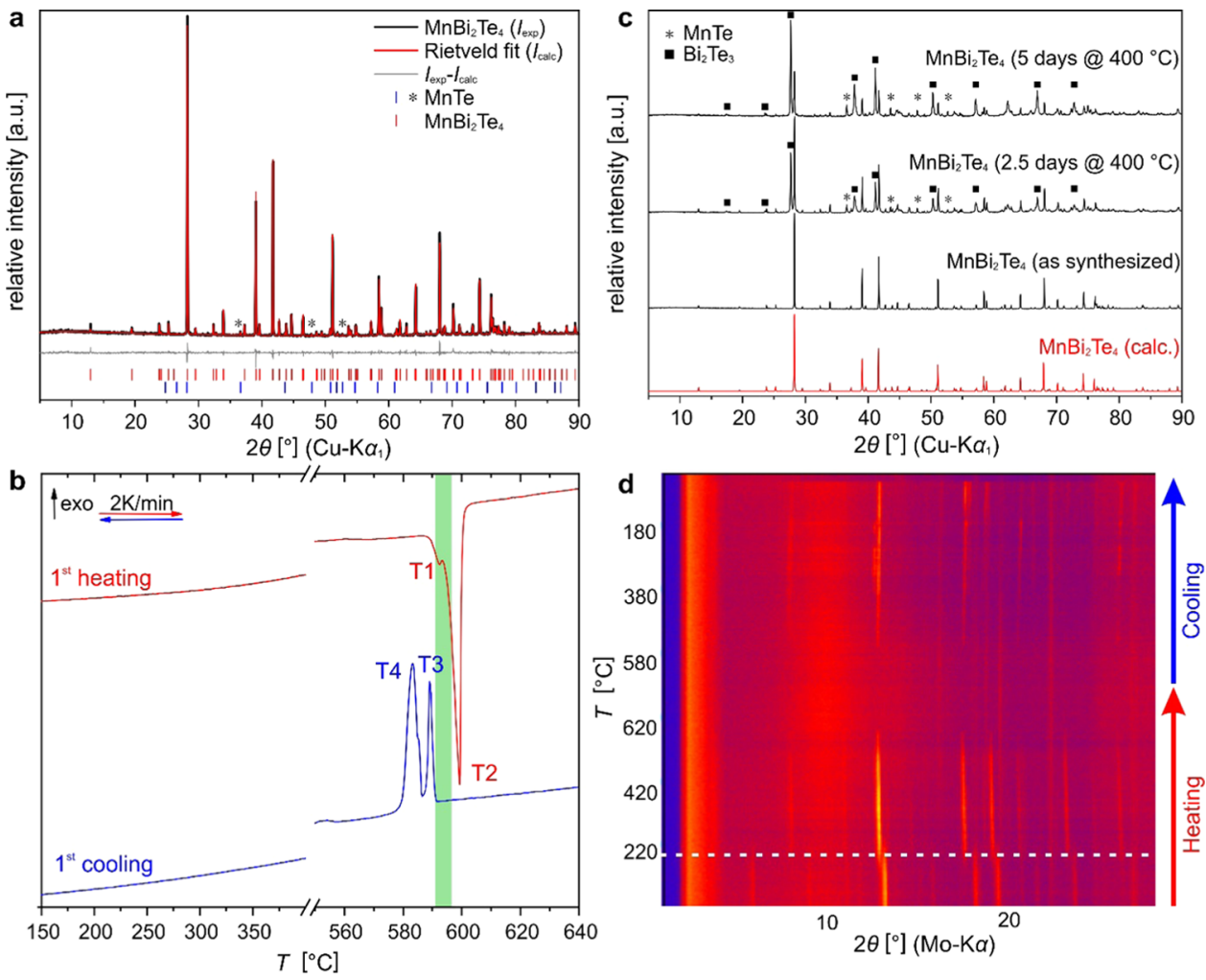

Figure 1. Powder synthesis and phase stability of $\mathrm{MnBi}_{2} \mathrm{Te}_{4}$. (a) Refined (red) and experimental (black) PXRD patterns of $\mathrm{MnBi}_{2} \mathrm{Te}_{4}$, sample \#2 prepared from a mixture of binaries by a solid-state reaction at $565{ }^{\circ} \mathrm{C}$. The strongest reflections of MnTe admixture are marked by asterisks. The MnTe fraction estimated by a Rietveld refinement is $2 \mathrm{wt} \%\left(R_{\mathrm{wp}}=0.08, R_{\mathrm{exp}}=0.08\right)$. (b) Heating and cooling runs of the differential scanning calorimetry (DSC) experiment on sample \#2. The determined Ostwald-Miers region between the peaks' onsets is marked in green. (c) PXRD patterns of the sample \#2 as-prepared and subjected to annealing at $400{ }^{\circ} \mathrm{C}$ for 2.5 and 5 days. All annealed samples were water-quenched. (d) Temperature-programmed PXRD pattern (Mo K $\alpha$ radiation) of a fine powder of $\mathrm{Mn}_{0.85} \mathrm{Bi}_{2.1} \mathrm{Te}_{4}$ heated from room temperature up to $620{ }^{\circ} \mathrm{C}$ and cooled back to room temperature at $2 \mathrm{~K} \mathrm{~min}^{-1}$. Decomposition of the ternary phase starting at ca. $220{ }^{\circ} \mathrm{C}$ is marked by a white dashed line.

materials. A prospective candidate magnetic TI, thus, should have a crystal structure resembling those of known topological insulators. Magnetic doping $(\mathrm{Mn}, \mathrm{Fe}, \mathrm{Cr}, \mathrm{V})$ in the classic topological insulators, above all in $\mathrm{Bi}_{2} \mathrm{Te}_{3}$, is faced with challenges. ${ }^{21} \mathrm{~A}$ material with a periodic crystal structure and an intrinsic magnetic ordering of metal atoms ordered in distinct crystallographic positions would be a highly desired alternative. An added asset would be van der Waals gaps that ensure a gradual change in the chemical potential at the interface and a less problematic experimental realization of heterostructures and devices.

The unique compound that fulfills these prerequisites, $\mathrm{MnBi}_{2} \mathrm{Te}_{4}$, has been put forward and scrutinized by theory $^{20,22-24}$ for some time after its discovery. ${ }^{25}$ The latter work has presented the synthesis of polycrystalline samples and a crystal-structure determination by the Rietveld method, thermoelectric properties of a composite material obtained by decomposition, and the calculated density of states. $\mathrm{MnBi}_{2} \mathrm{Te}_{4}$ is a layered compound built up by septuple layers $\infty_{\infty}^{2}[\mathrm{Te}-\mathrm{Bi}-$ $\mathrm{Te}-\mathrm{Mn}-\mathrm{Te}-\mathrm{Bi}-\mathrm{Te}]$ stacked in the rhombohedral $(\mathrm{ABC})$ fashion. It has to be noted that compounds offering a combination of bismuth (a bearer of strong spin-orbit coupling as an essential ingredient for a topological band inversion $^{1}$ ) and $3 \mathrm{~d}$ transition metals (cooperative magnetic phenomena) are sparse. ${ }^{26-31}$

To address the boosting interest of the TI community to $\mathrm{MnBi}_{2} \mathrm{Te}_{4}$, we herewith report the first crystal-growth technique based on thorough thermochemical studies, the structure refinement, a synthetic protocol for powder samples, and a phase-stability study of $\mathrm{MnBi}_{2} \mathrm{Te}_{4}$. We show that, despite the material's peculiar thermal behavior, synthesis of $\mathrm{MnBi}_{2} \mathrm{Te}_{4}$ can be scaled-up for various studies and applications. The synthetic protocols developed here enable the elucidation of the physical properties of $\mathrm{MnBi}_{2} \mathrm{Te}_{4}$ : whereas a preliminary characterization is given in this article, an in-depth study focusing on $\mathrm{MnBi}_{2} \mathrm{Te}_{4}$ as the first three-dimensional (3D) antiferromagnetic topological insulator (AFM TI) is reported elsewhere. ${ }^{32}$ This joint theory-experiment research provides the first confirmation of the AFM TI state since its prediction in $2010 .^{33}$ Follow-up studies ${ }^{34-36}$ support these claims and take a further step of proposing experimental setups, in which signatures of proximity-induced Majorana modes and quantized magnetoelectric effect could be observed in a real material $\mathrm{MnBi}_{2} \mathrm{Te}_{4}$. These prospects of functionalization generate a high demand for high-quality well-characterized samples.

\section{RESULTS AND DISCUSSION}

Powder Synthesis and Thermodynamic Stability. $\mathrm{MnBi}_{2} \mathrm{Te}_{4}$ was reported to be metastable ${ }^{25}$ based on the following observations. $\mathrm{A} \mathrm{MnBi}_{2} \mathrm{Te}_{4}$ powder sample was obtained after annealing of a fused, quenched ingot at 535 ${ }^{\circ} \mathrm{C}$ for $48 \mathrm{~h}$. It had decomposed into presumably nonstoichiometric $\mathrm{Bi}_{2} \mathrm{Te}_{3}$ and $\mathrm{MnTe}_{2}$ during an in situ hightemperature powder X-ray diffraction (PXRD) experiment, 
where the decomposition of the powder started at $150{ }^{\circ} \mathrm{C}$ and was complete at $500{ }^{\circ} \mathrm{C}$.

Following the procedure in ref 25 , we have synthesized a sample (\#1) from a stoichiometric mixture of the elements fused at $950{ }^{\circ} \mathrm{C}$ for 1 day, air-quenched, annealed at ca. $580{ }^{\circ} \mathrm{C}$ for 9 days, and air-quenched again. The polycrystalline product contained primarily $\mathrm{MnBi}_{2} \mathrm{Te}_{4}$ and a small admixture of $\mathrm{MnTe}$ (Figure S1, approx. 4 wt \% according to a Rietveld refinement).

Another sample (\#2) was obtained via a solid-state reaction from a stoichiometric mixture of presynthesized precursors, $\alpha$ MnTe (NiAs-type ${ }^{37}$ ) and $\mathrm{Bi}_{2} \mathrm{Te}_{3}$ (Figure S2). The sample was water-quenched. Prior to the annealing, the mixture was homogenized via ball-milling that, however, did not yield ternary products (Figure S3). Annealing at $565{ }^{\circ} \mathrm{C}$ for 10 days afforded a nearly phase-pure ternary product that contained about 2 wt \% MnTe (Figure 1), similar to sample \#1.

The similar outcome of these two experiments suggests that $\mathrm{MnBi}_{2} \mathrm{Te}_{4}$ may be thermodynamically stable in a limited temperature interval and may deviate from the idealized stoichiometric composition. These prerequisites are essential for the development of a crystal-growth strategy. Subsequently, the thermal stability of the synthesized $\mathrm{MnBi}_{2} \mathrm{Te}_{4}$ powders was studied by a combination of differential scanning calorimetry (DSC), long-term annealing at various temperatures, and temperature-programmed powder diffraction experiments (Figure 1, see also Supporting Information (SI) for a detailed discussion, Figures S4-S10, Table S1).

From the DSC experiments performed on a stoichiometric mixture of binary precursors (Figure S4) and on presynthesized $\mathrm{MnBi}_{2} \mathrm{Te}_{4}$ samples (Figure 1 for sample \#2, Figure $\mathrm{S} 7$ for sample \#1), we conclude that $\mathrm{MnBi}_{2} \mathrm{Te}_{4}$ melts at ca. $600{ }^{\circ} \mathrm{C}$ $\left(T_{\text {ons }}=595{ }^{\circ} \mathrm{C}, T_{\text {peak }}=599{ }^{\circ} \mathrm{C}\right)$. The exact character of melting could not be determined. $\mathrm{MnBi}_{2} \mathrm{Te}_{4}$ presumably melts incongruently since solidification of either $\mathrm{Bi}_{2} \mathrm{Te}_{3}$ or even some hitherto unknown ternary Mn-containing phase has been observed in the DSC cooling curves of all our samples (cf. SI). At subsolidus temperatures, the DSC data did not signal further decomposition of $\mathrm{MnBi}_{2} \mathrm{Te}_{4}$ (Figure S6), neither did they reflect the formation of $\mathrm{MnBi}_{2} \mathrm{Te}_{4}$ upon heating.

In contrast to that, long-term annealing of the presynthesized $\mathrm{MnBi}_{2} \mathrm{Te}_{4}$ powders (sample \#2) at $400{ }^{\circ} \mathrm{C}$ and below results in their inevitable decomposition into $\mathrm{Bi}_{2} \mathrm{Te}_{3}$ and $\mathrm{MnTe}$ (Figure 1). Decomposition takes days and proceeds notably slower at $200{ }^{\circ} \mathrm{C}$ than at $400{ }^{\circ} \mathrm{C}$. Nevertheless, this process is reversible as the obtained phase mixtures can recombine into $\mathrm{MnBi}_{2} \mathrm{Te}_{4}$ if the above-described synthesis procedures are repeated. The decomposition rate appears to depend on the particle size: finely dispersed powders decompose faster at lower temperatures than coarse powders or compacted bulk with the same phase composition.

As opposed to the DSC data (Figure S6), temperatureprogrammed powder diffraction on presynthesized $\mathrm{MnBi}_{2} \mathrm{Te}_{4}$ (sample \#1) up to ca. $650{ }^{\circ} \mathrm{C}$ concerted with the results in ref 25. At a heating rate of $2 \mathrm{~K} \mathrm{~min}^{-1}$, decomposition of $\mathrm{MnBi}_{2} \mathrm{Te}_{4}$ into $\mathrm{Bi}_{2} \mathrm{Te}_{3}$ and, presumably, manganese tellurides has commenced already at ca. $200{ }^{\circ} \mathrm{C}$ (Figure 1) and was faster in finely ground powders. Upon cooling, $\mathrm{MnBi}_{2} \mathrm{Te}_{4}$ did not form, unless the mixture was fused again, repeating the original synthesis protocol. This might be explained by rather macroscopic phase separation. In a similar way, the phase composition and crystallinity of larger bulk samples depend on the quenching/cooling rates. The fraction of $\mathrm{MnBi}_{2} \mathrm{Te}_{4}$ significantly increased at sufficiently slow cooling rates $(6 \mathrm{~K}$ $\mathrm{h}^{-1}$ ) (Figure S10).

These seemingly contradictory results point at strong kinetic hindrances in the formation and decomposition of $\mathrm{MnBi}_{2} \mathrm{Te}_{4}$. An increased mobility in the melt may be a beneficial factor for the formation of $\mathrm{MnBi}_{2} \mathrm{Te}_{4}$. To conclude the discussion of phase stability, we put forward an assumption that $\mathrm{MnBi}_{2} \mathrm{Te}_{4}$ is thermodynamically stable in a rather narrow high-temperature interval below $600{ }^{\circ} \mathrm{C}$, and its decomposition in compact bulk may be hindered due to an interplay of diffusion and strain. The formation temperature lies somewhat between $400{ }^{\circ} \mathrm{C}$ (our data) and $535{ }^{\circ} \mathrm{C}^{25}$ but remains to be determined. Owing to this kinetic barrier, powder crystalline samples of $\mathrm{MnBi}_{2} \mathrm{Te}_{4}$, which were synthesized within the phase-stability interval, can be quenched down to room temperature, where $\mathrm{MnBi}_{2} \mathrm{Te}_{4}$ is metastable. Compacted bulk samples and crystals can be used for physical property measurements (vide infra) at low and slightly elevated temperatures without showing signs of massive decomposition.

The issue of phase purity is intimately related to this point. All powder samples contained minor side phases, typically MnTe, that were detected by PXRD and/or by energydispersive X-ray spectroscopy (EDX). These ubiquitous admixtures could stem from partial decomposition upon quenching, as just discussed above, or from an incomplete reaction of the starting materials. MnTe remains solid when $\mathrm{Bi}_{2} \mathrm{Te}_{3}$ is already molten, so the reaction is always heterogeneous. Nonstoichiometry of the title compound is yet another possible explanation. An additional signal in the DSC heating curve of sample \#2 (Figure 1) could indicate a eutectic between MnTe and the ternary phase. Following this argument, decomposition of the latter could be associated with phase relations that do not involve the ternary phase. Moreover, single-crystal X-ray diffraction (SCXRD) experiments establish that the title compound could tolerate a significant degree of nonstoichiometry (vide infra). However, experiments targeting a nonstoichiometric variant $\mathrm{Mn}_{0.85} \mathrm{Bi}_{2.1} \mathrm{Te}_{4}$ by both synthesis routes \#1 and \#2 have also yielded a nearly phase-pure sample according to PXRD (Figure S11). Small admixtures of $\mathrm{MnTe}_{2}$ instead of $\mathrm{MnTe}$ point at a possible redox reaction. One possible mechanism is the reduction to $\mathrm{Bi}^{0}$ and formation of bismuth-rich tellurides instead of/alongside $\mathrm{Bi}_{2} \mathrm{Te}_{3}$; however, low amounts of the admixtures do not allow a reliable Rietveld refinement. The thermal behavior of these samples in DSC experiments was similar to that of the previously studied samples (Figure S12 and the discussion in the SI). So, we conclude that the phase purity of $\mathrm{MnBi}_{2} \mathrm{Te}_{4}$ samples is mainly determined by its finite temperature-stability window.

Crystal Growth Optimization. The acquired knowledge about the phase-stability range and decomposition peculiarities made it possible to develop a crystal-growth route for $\mathrm{MnBi}_{2} \mathrm{Te}_{4}$. The small energetic difference between the formation enthalpies of $\mathrm{Bi}_{2} \mathrm{Te}_{3}$ and $\mathrm{MnBi}_{2} \mathrm{Te}_{4}$ is indicated by a gap of only $9 \mathrm{~K}$ between the melting temperatures of $\mathrm{Bi}_{2} \mathrm{Te}_{3}$ and $\mathrm{MnBi}_{2} \mathrm{Te}_{4}$ (and less than $6 \mathrm{~K}$ in the solidification temperatures due to different undercooling). These findings suggest that single-crystal growth can proceed via slow cooling over the very narrow Ostwald-Miers region between the onset temperatures of melting (signal $\mathrm{T}_{2}$ ) and solidification (signal $\mathrm{T}_{3}$ ) (cf. Figure 1). Indeed, single crystals were obtained by slow cooling in the Ostwald-Miers region (ca. $3 \mathrm{~K}$ wide) followed by annealing for several days. All samples were water- 


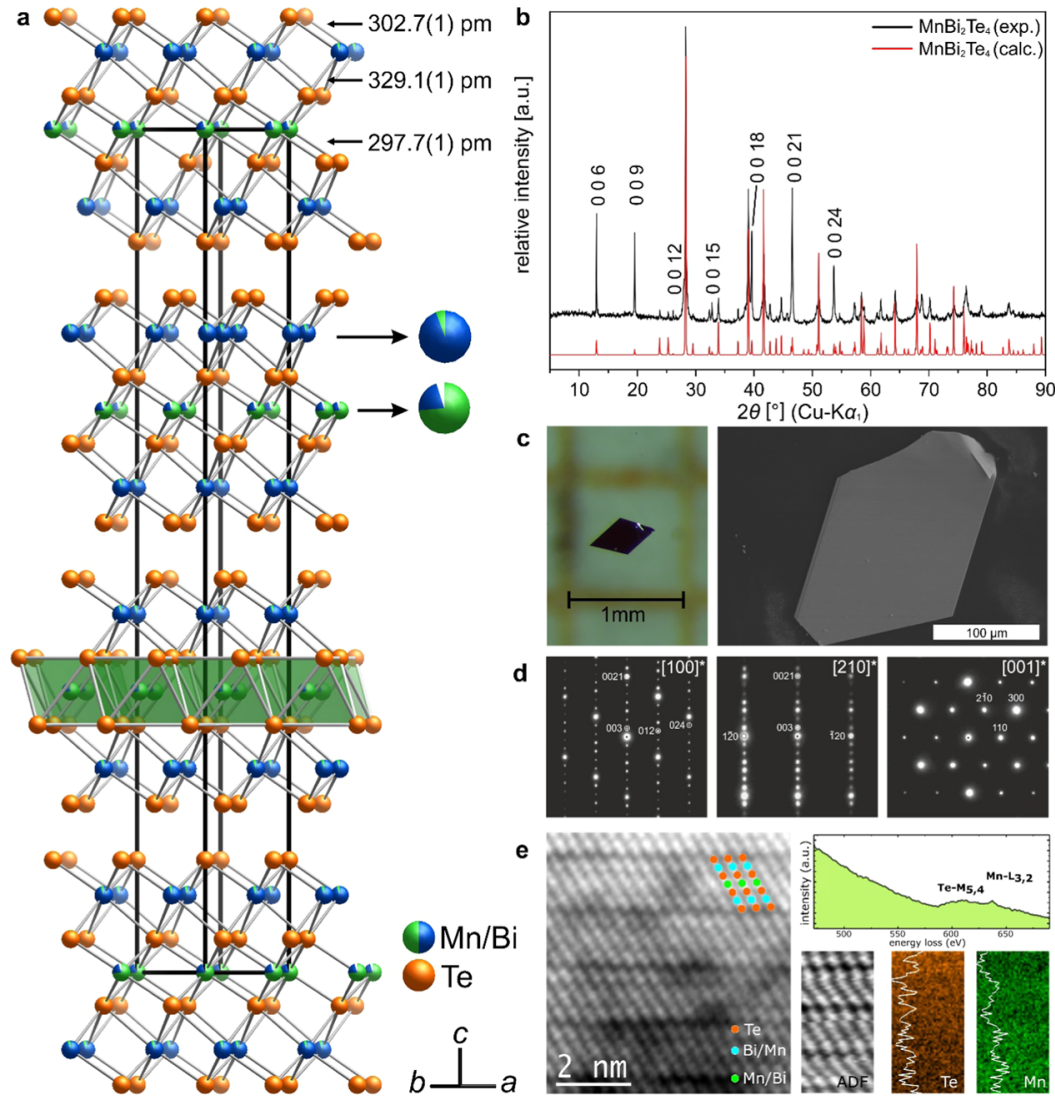

Figure 2. Crystal structure and cation intermixing. (a) Crystal structure of the $\mathrm{Mn}_{0.85(3)} \mathrm{Bi}_{2.10(3)} \mathrm{Te}_{4}$ model with mixed site occupancies and $U_{\text {iso }}$ with 99\% probability. Selected $\mathrm{Mn}-\mathrm{Te}$ and $\mathrm{Bi}-\mathrm{Te}$ interatomic distances are listed. (b) PXRD of ground crystals prepared via slow cooling $\left(6 \mathrm{~K} \mathrm{~h}^{-1}\right)$ and long-term annealing below the established Ostwald-Miers region. Note strong preferred orientation along [001] in comparison with Figure 1a. (c) As-grown $\mathrm{MnBi}_{2} \mathrm{Te}_{4}$ crystals used for measurements of physical properties (left) and SCXRD (right). (d) Main-zone selected area electron diffraction (SAED) patterns of a $\mathrm{MnBi}_{2} \mathrm{Te}_{4}$ crystallite. Indexing accords with the unit cell found by SCXRD (Tables 1 and S2). (e) An high angle annular dark field (HAADF) image of a $\mathrm{MnBi}_{2} \mathrm{Te}_{4}$ crystallite. Te (orange), $\mathrm{Bi}$ (blue), and $\mathrm{Mn}$ (green) columns are color-coded with respect to the ordered crystal structure. The elemental distribution of $\mathrm{Mn}$ and $\mathrm{Te}$ extracted from the electron energy loss (EEL) spectrum image using the Te$\mathrm{M}_{5,4}$ and the $\mathrm{Mn}-\mathrm{L}_{3,2}$ edge of the $\mathrm{MnBi}_{2} \mathrm{Te}_{4}$ crystal. The top panel shows the summed EEL spectra; the bottom panel shows the ADF image as well as the Te-M (orange) and $\mathrm{Mn}-\mathrm{K}$ (green) distribution. Integrated intensities of the Te-M and the Mn-L edge images are depicted by white lines.

Table 1. Crystallographic Data for $\mathrm{Mn}_{0.85(3)} \mathrm{Bi}_{2.10(3)} \mathrm{Te}_{4}$, Refined with Bi Antisite Defects and Mn Vacancies, from an SCXRD Experiment

crystal system, space group

formula units

lattice parameters

temperature

range for data collection; index ranges

collected reflections

$R$ indices of merging

structure refinement

data/restraints/parameters

final $R$ indices and goodness-of-fit on $F^{2}$

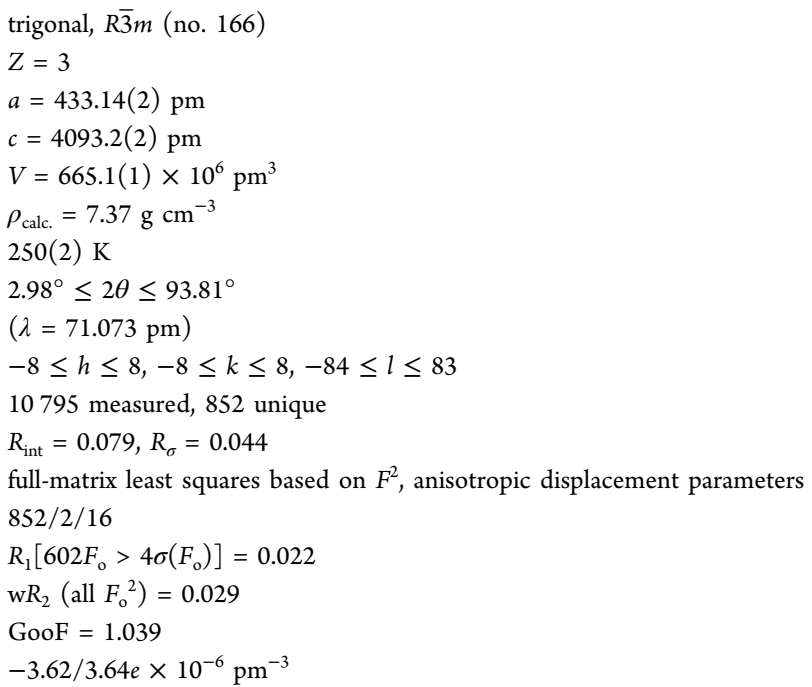

quenched. Platelet-shaped crystals with diameters up to 200 $\mu \mathrm{m}$ were obtained within and atop of a highly crystalline ingot. Our PXRD analysis of both crystals and the ingot revealed nearly phase-pure $\mathrm{MnBi}_{2} \mathrm{Te}_{4}$ (Figure 2) with a strongly preferred orientation along the [001] direction. It should be noted that the polycrystalline samples obtained in this way 
were never absolutely phase-pure as indicated by slight asymmetry of some reflections in Figure 2.

Crystal-Structure Refinement. We were now able to elucidate the crystal structure of $\mathrm{MnBi}_{2} \mathrm{Te}_{4}$ by SCXRD. In agreement with previously reported powder data, ${ }^{25} \mathrm{MnBi}_{2} \mathrm{Te}_{4}$ crystallizes in the centrosymmetric space group $R \overline{3} m$ (no. 166) with the lattice parameters $a=4.3314(2) \AA$ and $c=40.932(2)$ Å. Electron diffraction patterns collected on a wedge of a thin lamella cut out from a single crystal agree well with the trigonal symmetry and the unit cell found in SCXRD (Figure 2).

The reported crystal structure of $\mathrm{MnBi}_{2} \mathrm{Te}_{4}{ }^{25}$ belongs to the ordered so-called "GeAs $\mathrm{Te}_{4}$ " structure type, which comprises septuple layers. However, the experimental electron density did not correspond to two specific fully occupied $\mathrm{Mn}$ and $\mathrm{Bi}$ positions. Cation intermixing is ubiquitous in the abundant mixed $\mathrm{TtBi}_{2} \mathrm{Te}_{4}, \mathrm{Tt}=\mathrm{Ge}, \mathrm{Pb}$, Sn semiconductors. ${ }^{38}$ Moreover, reported ordered models have only been postulated, whereas structure refinements have always yielded cation disorder, although compounds of this structure type typically do not contain $3 \mathrm{~d}$ metals with an exception of rare instances of doping. ${ }^{39}$

For this reason, cation intermixing in the $\mathrm{Bi}$ and $\mathrm{Mn}$ sites in $\mathrm{MnBi}_{2} \mathrm{Te}_{4}$ was taken into account. We considered antisite defects ( $\mathrm{Bi}$ in the $\mathrm{Mn}$ site and vice versa) and cation vacancies (Figure S13 and Tables 1, 2, S2-S7). Charge neutrality of the

Table 2. Crystallographic Data for $\mathbf{M n}_{0.85(3)} \mathbf{B i}_{2.10(3)} \mathbf{T e}_{4}$, Refined with Bi Antisite Defects and Mn Vacancies, from an SCXRD Experiment

\begin{tabular}{rlllll} 
atom & \multicolumn{1}{c}{$x$} & \multicolumn{1}{c}{$y$} & \multicolumn{1}{c}{$z$} & $U_{\mathrm{eq}} / \mathrm{pm}^{2}$ & $\mathrm{SOF}$ \\
Bi1 6c & $1 / 3$ & $2 / 3$ & $0.09173(2)$ & $182(1)$ & $0.943(1)$ \\
Bi2 3a & 0 & 0 & 0 & $172(1)$ & $0.215(1)$ \\
Mn1 6c & $1 / 3$ & $2 / 3$ & $0.09173(2)$ & $182(1)$ & $0.057(1)$ \\
Mn2 3a & 0 & 0 & 0 & $172(1)$ & $0.736(1)$ \\
Te1 6c & $2 / 3$ & $1 / 3$ & $0.03947(2)$ & $170(1)$ & 1 \\
Te2 6c & 0 & 0 & $0.13337(2)$ & $169(1)$ & 1 \\
\hline
\end{tabular}

title compound was assumed in the structure refinements under the restraint of eight positive charges per formula unit. The oxidation states in the stoichiometric variant can be directly ascribed to $\mathrm{Mn}^{\mathrm{II}}\left(\mathrm{Bi}^{\mathrm{III}}\right)_{2}\left(\mathrm{Te}^{-\mathrm{II}}\right)_{4}$, similar to structurally related compounds like $\mathrm{GeBi}_{2} \mathrm{Te}_{4}{ }^{40}$ This also seems realistic from a chemical viewpoint since tellurium is not expected to oxidize manganese to its higher oxidation states.

The resultant nonstoichiometric $\mathrm{Mn}_{0.85(3)} \mathrm{Bi}_{2.10(3)} \mathrm{Te}_{4}$ model comprises $21.5(1) \% \mathrm{Bi}, 73.6(1) \% \mathrm{Mn}$, and $4.9(1) \%$ voids on the 3a position, whereas the $\mathrm{Bi}$ site (6c) has $5.7(1) \%$ of $\mathrm{Mn}$ antisite defects (Figure 2). Vacancies were allowed only in the $3 \mathrm{a}$ position; they were considered less probable for the $6 \mathrm{c}$ site since the Te atoms border a van der Waals gap and already have only three bonding partners.

Cation intermixing is a structural hallmark; a hypothetical ordered structure model yields a nonstable refinement. Since the presence of vacancies is less significant, a second model without vacancies but still with mixed occupancies of both cation positions was considered (Tables S4-S7). However, it yielded only slightly higher $R$-factors. In this scenario, the $\mathrm{Mn}$ site has $17.5(1) \%$ of $\mathrm{Bi}$ antisite defects, whereas the $\mathrm{Bi}$ site (with twice the multiplicity of the Mn site) hosts 8.8(1)\% Mn defects. The restraint of the charge neutrality was also applied in this solution so that the sum formula is $\mathrm{MnBi}_{2} \mathrm{Te}_{4}$.
To further elaborate the details of the crystal structure, highresolution scanning transmission electron microscopy (HRSTEM) imaging and local elemental mapping using electron energy loss spectroscopy (EELS) were used. Figure 2 summarizes the results in the $[100]^{*}$ zone axis. Even though the investigation was conducted at $80 \mathrm{kV}$ acceleration voltage only, sample damage due to the electron beam could not be avoided completely and made the analysis challenging. As can be seen from the intensity of the high angle annular dark field (HAADF) image, the single atomic planes vary in their intensity distribution. The intensity scales approximately linearly with the line integral of the atomic numbers that are each raised to a power of about 1.7. The strong intensity in the central atomic columns of a septuple layer is surprising, as this position is expected to be mainly occupied by $\mathrm{Mn}$ atoms and only by a small fraction of $\mathrm{Bi}$ atoms. Using local elemental mapping by analyzing the EELS spectra of the scanned area, $\mathrm{Mn}$ and Te distributions have been visualized. It is found that $\mathrm{Mn}$ is distributed over the septuple layer instead of being localized solely in its central atomic plane, thus corroborating the results of X-ray diffraction.

Based on the available results, we cannot make a conclusive choice for one of the structure models. Summing up, it seems likely that the structure type tolerates some variations in the site occupancies. In an attempt to tackle this issue with EDX, spectra of several crystals (averaged over ca. 10 points for each) were quantified using stoichiometric $\mathrm{Bi}_{2} \mathrm{Te}_{3}$ and $\mathrm{MnTe}$ as references. Averaging of the obtained data over the different choices of the reference compound (e.g., for Te) and edges (Bi-M or Bi-L) used for quantification has resulted in the composition (in atom \%) Mn 11.5(9), Bi 31(1), and Te 58(2), corresponding to $\mathrm{Mn}_{0.81(6)} \mathrm{Bi}_{2.1(2)} \mathrm{Te}_{4}$. The rather large uncertainties in the quantification of the heavy element concentration stem likely from systematic errors introduced by different edges and reference choices and do not allow us to distinguish between the two structure models, $\mathrm{Mn}_{0.85(3)} \mathrm{Bi}_{2.10(3)} \mathrm{Te}_{4}$ and $\mathrm{MnBi}_{2} \mathrm{Te}_{4}$.

Our powder synthesis yielded nearly phase-pure samples for both compositions (vide supra). Thus, solid solutions $\mathrm{Mn}_{1-x} \mathrm{Bi}_{2+2 x / 3} \mathrm{Te}_{4}$, which necessitate charge neutrality, assuming $\mathrm{Mn}(\mathrm{II}), \mathrm{Bi}(\mathrm{III})$, and $\mathrm{Te}(-\mathrm{II})$, appear to be likely. This is not unusual with respect to related compounds (Ge$\mathrm{Te})_{n} \mathrm{Sb}_{2} \mathrm{Te}_{3}$ : they do not always form the structure type that is initially suggested by the composition. ${ }^{41}$ Furthermore, intrinsic phenomena of pronounced $\mathrm{Mn} / \mathrm{Bi}$ intermixing and nonstoichiometry have been accounted and discussed in chainlike $\mathrm{Mn}_{1-x} \mathrm{Bi}_{2+y} \mathrm{Q}_{4}(\mathrm{Q}=\mathrm{S}, \mathrm{Se})^{42,43}$ structures and their Sn-substituted derivatives. ${ }^{44}$ Worth noting is that stoichiometric " $\mathrm{MnBi}_{2} \mathrm{Se}_{4}$ " could not be synthesized. ${ }^{42}$ For the sake of convenience, we continue to use the sum formula $\mathrm{MnBi}_{2} \mathrm{Te}_{4}$ instead of $\mathrm{Mn}_{1-x} \mathrm{Bi}_{2+2 x / 3} \mathrm{Te}_{4}$ throughout the following text.

An interesting structural aspect is that $\mathrm{MnBi}_{2} \mathrm{Te}_{4}$ strongly resembles the classic $\mathrm{TI}, \mathrm{Bi}_{2} \mathrm{Te}_{3}$. The septuple layers of the former may be regarded as a flat arrangement of edge-sharing Mn-centered telluride octahedra incorporated into the quintuple layers of $\mathrm{Bi}_{2} \mathrm{Te}_{3}$. Once again, $\mathrm{Bi}$ and $\mathrm{Mn}$ do not engage into direct bonding, as they occupy the octahedral voids in a close-packed array of $\mathrm{Te}$ atoms and, thus, reside at the nearest distances of 4.33 or $4.51 \AA$. The coordination of the $\mathrm{Bi}$ atoms is asymmetric: the $\mathrm{Bi}-\mathrm{Te}$ distances toward the $\mathrm{Mn}$ layer are notably longer than the $\mathrm{Bi}-\mathrm{Te}$ toward the van der Waals gap (Figure 2). Thus, $\mathrm{MnBi}_{2} \mathrm{Te}_{4}$ could be regarded as $(\mathrm{BiTe})^{+}\left(\mathrm{MnTe}_{2}\right)^{2-}\left(\mathrm{BiTe}^{+}\right)$in a semi-ionic model, similar to 

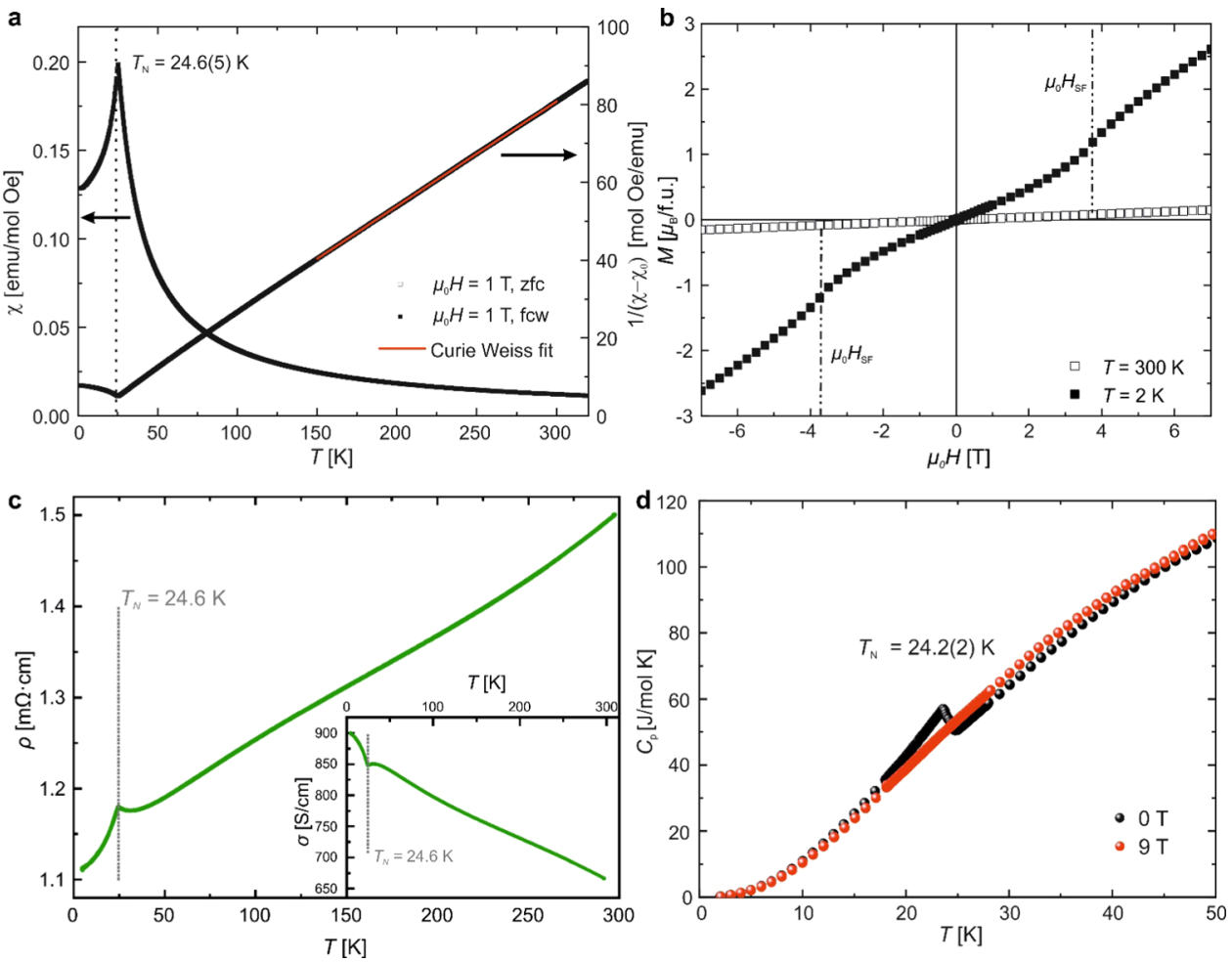

Figure 3. Magnetic and transport characterization of polycrystalline (a, b) and single-crystal (c, d) specimens. (a) Temperature-dependent magnetic susceptibility measurements of a melt ingot $\mathrm{Mn}_{0.85} \mathrm{Bi}_{2.1} \mathrm{Te}_{4}$ and its inverse in an external magnetic field of $1 \mathrm{~T}$ show an antiferromagnetic transition at $T_{\mathrm{N}}=24.6(5) \mathrm{K}$. (b) Field-dependent magnetic moment measurements of a melt ingot $\mathrm{Mn}_{0.85} \mathrm{Bi}_{2.1} \mathrm{Te}_{4}$. (c) In-plane electrical resistivity of a single-crystal $\mathrm{MnBi}_{2} \mathrm{Te}_{4}$; the inset shows the respective electrical conductivity. (d) Specific heat measurements of several single crystals.

$(\mathrm{BiTe})^{+} \mathrm{I}^{-} .^{45}$ These crystal-chemical similarities may inspire the design of modular structures between the title compound and $\mathrm{Bi}_{n} \mathrm{TeX}, \mathrm{X}=\mathrm{I}, \mathrm{Br}$ topological materials. ${ }^{46,47}$ The structural compatibility may enable a strong overlap between the topological surface states of $\mathrm{Bi}_{2} \mathrm{Te}_{3}$ or $\mathrm{Bi}_{n} \mathrm{TeX}$ and the spinpolarized interface states of $\mathrm{MnBi}_{2} \mathrm{Te}_{4}$. The first example has already been considered theoretically in a model of a septuple $\infty^{2}[\mathrm{Te}-\mathrm{Bi}-\mathrm{Te}-\mathrm{Mn}-\mathrm{Te}-\mathrm{Bi}-\mathrm{Te}]$ overlay atop of semifinite $\mathrm{Bi}_{2} \mathrm{Te}_{3}$ bulk. ${ }^{19}$

Magnetic and Transport Properties. The magnetic characteristics of a polycrystalline melt ingot $\mathrm{Mn}_{0.85} \mathrm{Bi}_{2.1} \mathrm{Te}_{4}$ (route \#1) are presented in Figure 3. Long-range antiferromagnetic ordering establishes at temperatures below $T_{\mathrm{N}}=$ 24.6(5) $\mathrm{K}$, whereas the paramagnetic regime $(150-300 \mathrm{~K})$ resembles a Curie-Weiss law, $\chi(T)=\chi_{0}+C /\left(T-\theta_{\mathrm{CW}}\right)$. Here, $\chi_{0}$ stands for a small temperature-independent magnetic susceptibility of both diamagnetic closed electron shells and a Pauli paramagnetic contribution due to some metallicity in this material. The fitted values for the effective moment and the Curie-Weiss temperature are $\mu_{\text {eff }}=5.9(1) \mu_{\mathrm{B}}$ and $\theta_{\mathrm{CW}}=$ $+1(3) \mathrm{K}^{48} \mathrm{We}$ do not find any additional magnetic contribution associated with $\mathrm{Mn}$ antisite defects in the $\mathrm{Bi}$ sites. The $M(H)$ curve at $2 \mathrm{~K}<T_{\mathrm{N}}$ further shows an indicative spin-flop transition at $\mu_{0} H_{\mathrm{SF}}=3.7(2) \mathrm{T}$. Magnetic anisotropy measured on a stoichiometric $\mathrm{MnBi}_{2} \mathrm{Te}_{4}$ sample is in good agreement with these data and is scrutinized elsewhere in the context of topological properties. ${ }^{32}$ According to DFT $+\mathrm{U}$ calculations, ${ }^{22}$ the ground state of the ideally ordered bulk $\mathrm{MnBi}_{2} \mathrm{Te}_{4}$ corresponds to an interlayer antiferromagnet with ferromagnetic intralayer coupling.

Our temperature-dependent specific heat measurements on an assembly of several single crystals (Figure 3) demonstrate a nonsingular increase at $T_{\mathrm{N}} \sim 24.2(2) \mathrm{K}$ accompanying the antiferromagnetic ordering that is characteristic for a secondorder phase transition. It is broadened and nearly suppressed in fields $H>H_{c}$ (e.g., $9 \mathrm{~T}$ ) applied perpendicular to (001).

Complementary to the magnetic properties, the temperature dependence of the in-plane electrical resistivity $\rho(T)$ of a $\mathrm{MnBi}_{2} \mathrm{Te}_{4}$ crystal was measured from room temperature down to $T=4.5 \mathrm{~K}$. It shows an approximately linear decrease of the resistivity upon lowering the temperature, which is characteristic for metals (Figure 3). Below $50 \mathrm{~K}, \rho(T)$ deviates from linearity and exhibits a distinct peaklike feature centered at $24.6 \mathrm{~K}$. The local increase indicates an enhanced electron scattering in the vicinity of a magnetic phase transition, and a sharp decrease below the peak signals the freezing-out of the scattering due to an onset of long-range magnetic order, respectively. ${ }^{49}$ This is consistent with our present magnetic susceptibility and specific heat data. In the antiferromagnetically ordered state, the resistivity roughly follows a power law $\rho(T)=\rho(0)+a T^{b}$ with an exponent $b=2.2$ and an offset $\rho(0)$ $=1.1 \mathrm{~m} \Omega \mathrm{cm}$, resulting in a residual-resistivity ratio (RRR) of $\rho(300) / \rho(0) \approx 1.35$. We note that the RRR determined across the $3 \mathrm{D}$ magnetic phase transition is of limited applicability because of the associated change in the electronic structure and the freezing-out of scattering. However, despite the tendency of these effects to cause an enhanced RRR, the obtained value is still rather low compared to typical metals, indicating a high impurity scattering rate. The room temperature electrical conductivity of $\sigma=670 \mathrm{~S} \mathrm{~cm}^{-1}$ is much higher than the previously reported $\sigma=39 \mathrm{~S} \mathrm{~cm}^{-1},{ }^{25}$ bringing it much closer to known values of structurally related compounds such as $\mathrm{GeBi}_{2} \mathrm{Te}_{4}\left(500 \mathrm{~S} \mathrm{~cm} \mathrm{~cm}^{-1}\right), \mathrm{SnBi}_{2} \mathrm{Te}_{4}\left(345 \mathrm{~S} \mathrm{~cm}^{-1}\right)$, and $\mathrm{PbBi}_{2} \mathrm{Te}_{4}\left(1670 \mathrm{~S} \mathrm{~cm}^{-1}\right)$ at room temperature. ${ }^{38}$ 

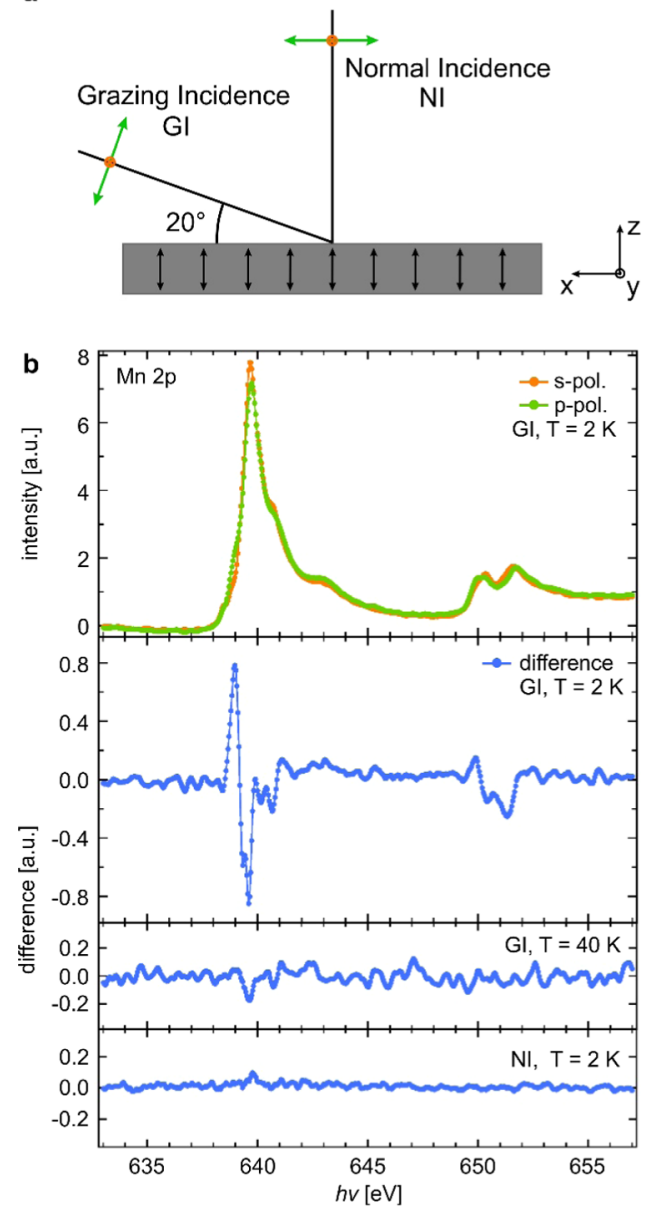
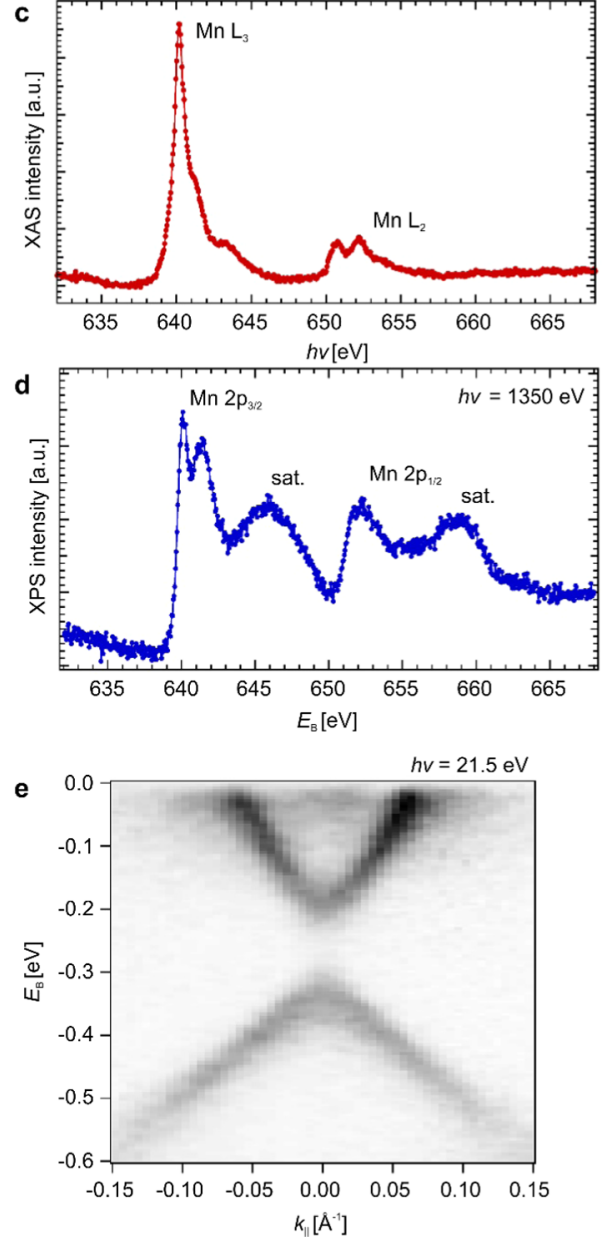

Figure 4. X-ray linear dichroism (XLD) and XAS measurements for a $\mathrm{MnBi}_{2} \mathrm{Te}_{4}(001)$ single crystal. (a) Experimental geometry of X-ray magnetic linear dichroism (XMLD) measurements performed in grazing and normal light incidence (GI and NI). (b) XAS data sets of the Mn $\mathrm{L}_{2,3}$ absorption edge obtained using s- and p-polarized light. XMLD signal, i.e., the difference between the two above data sets obtained in GI and NI. (c) $\mathrm{Mn} \mathrm{L}_{2,3}$ absorption edge (XAS) for $\mathrm{MnBi}_{2} \mathrm{Te}_{4}$ measured in total electron yield (TEY) mode. (d) XPS Mn $2 \mathrm{p}$ spectrum for $\mathrm{MnBi}_{2} \mathrm{Te}_{4}$ obtained at $h \nu=1350 \mathrm{eV}$. (e) Angle-resolved photoemission (ARPES) data near the Fermi level for $\mathrm{MnBi}_{2} \mathrm{Te}_{4}(001)$ obtained with p-polarized light at $h \nu=$ $21.5 \mathrm{eV}(T=18 \mathrm{~K})$.

Spectroscopic Characterization. The electronic and magnetic properties of $\mathrm{MnBi}_{2} \mathrm{Te}_{4}(001)$ single crystals were studied by X-ray photoelectron spectroscopy (XPS) and X-ray absorption spectroscopy (XAS). The XAS line shape of the Mn $\mathrm{L}_{2,3}$ absorption edge (Figure 4) confirms the $\mathrm{Mn}^{\mathrm{II}}$ valence state, based on a comparison to reference data on different $\mathrm{Mn}$ oxides and fluorides, namely, $\mathrm{MnO}, \mathrm{Mn}_{2} \mathrm{O}_{3}, \mathrm{MnO}_{2}, \mathrm{MnF}_{2}$, and $\mathrm{MnF}_{3}{ }^{50,51}$ Similarly, the XPS line shapes of the Mn $2 \mathrm{p}$ levels (Figure 3) resemble spectra of $\mathrm{Mn}$ compounds in which $\mathrm{Mn}$ is divalent. ${ }^{52,53}$ In particular, the satellites, located approximately $6 \mathrm{eV}$ below the two main lines, are characteristic of $\mathrm{Mn}^{\mathrm{II}}{ }^{54}$ Both XPS and XAS show no evidence for the presence of two different Mn species, despite two possible $\mathrm{Mn}$ atomic positions, which were established by XRD and EELS in the previous section. We therefore expect the chemical states of the $\mathrm{Mn}$ ions on the $6 \mathrm{c}$ and $3 \mathrm{a}$ sites to be similar and, thus, without considerable differences in the XAS/XPS line shapes and positions.

The band structure of $\mathrm{MnBi}_{2} \mathrm{Te}_{4}(001)$ near the Fermi level has been examined by angle-resolved photoelectron spectroscopy (ARPES). We observe an upper electron-like feature and a lower holelike feature that are separated by an energy gap at the $\bar{\Gamma}$ point $\left(k_{\|}=0\right)$ of approximately $100 \mathrm{meV}$ (Figure 4).
The measured bands may be interpreted as a gapped Dirac cone, which is indeed expected for a topological insulator with intrinsic out-of-plane magnetization. Comprehensive analysis of the ARPES data corroborated by ab initio calculations is reported elsewhere. ${ }^{32}$ Furthermore, the ARPES measurements indicate an $\mathrm{n}$-doped character of $\mathrm{MnBi}_{2} \mathrm{Te}_{4}$, in contrast to the p-type semiconductor in ref 25.

X-ray linear dichroism (XLD) data collected in the total electron yield (TEY) mode (Figure 4) confirm the present magnetic characterization and earlier theoretical predictions. ${ }^{22}$ Measurements performed in grazing light incidence geometry at $T=2 \mathrm{~K}$ show a clear XLD signal, indicative of an out-ofplane anisotropy of the $\mathrm{Mn} 3 \mathrm{~d}$ charge distribution. At $T=40$ $\mathrm{K}$, i.e., above $T_{\mathrm{N}}$, no XLD signal is detected anymore, which confirms the magnetic origin of the XLD signal at low $T$, as opposed to a crystal field effect. The out-of-plane nature of the magnetic state is further supported by the absence of an XLD signal at $T=2 \mathrm{~K}$ in normal light incidence geometry. The probing depth of the XLD experiment is on the order of only several nanometers, which implies that the out-of-plane magnetic state extends toward the surface.

Thermoelectric Characterization. Earlier reported thermoelectric properties of $\mathrm{MnBi}_{2} \mathrm{Te}_{4}$ powders measured under a 

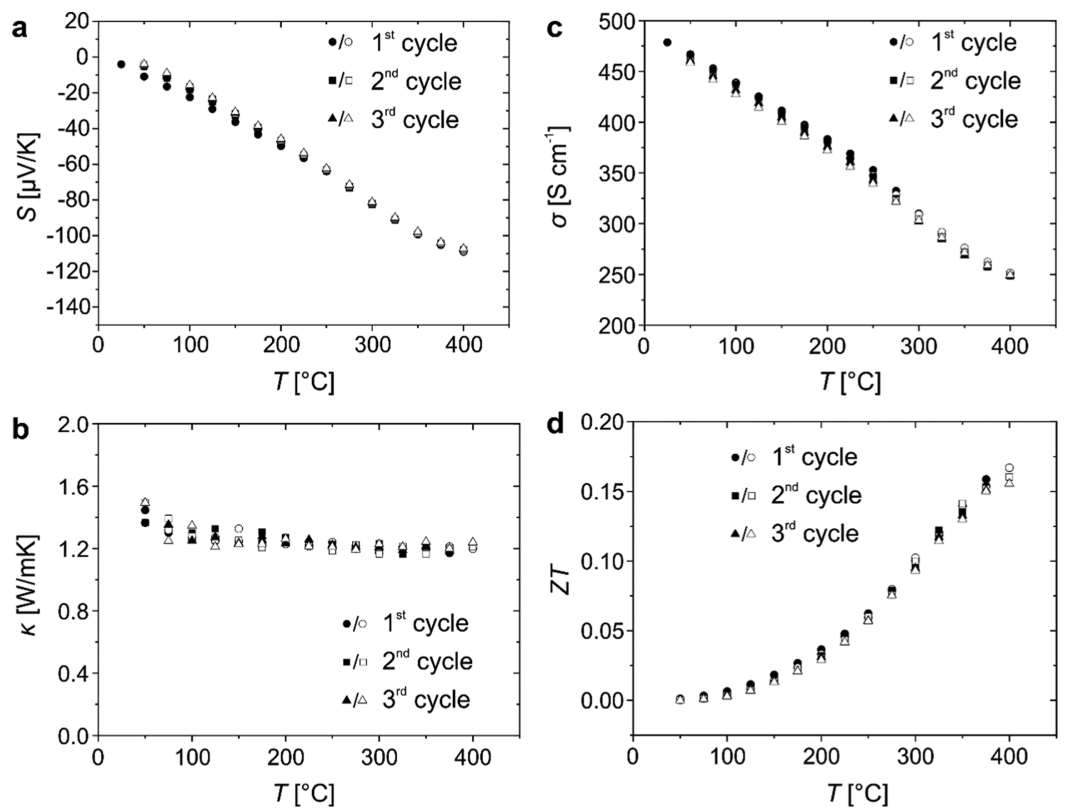

Figure 5. Thermoelectric characterization of $\mathrm{Mn}_{0.85} \mathrm{Bi}_{2.1} \mathrm{Te}_{4}$ ingot measured in three consecutive cycles. (a) Seebeck coefficient $S$. (b) Thermal conductivity $\kappa$. (c) Electrical conductivity $\sigma$. (d) Thermoelectric figure of merit $Z T$ as a function of temperature. Filled symbols: heating, open symbols: cooling.

protective helium atmosphere were not reversible and showed quick deterioration after heating above ca. $277^{\circ} \mathrm{C} .{ }^{25}$ Moreover, an optical band gap of $0.4 \mathrm{eV}$ was estimated from the diffuse reflectance of a sample that was assumed to be p-conducting, judging from a positive Seebeck coefficient.

We used a piece of preannealed (Figure S14, route \#1), polycrystalline, compact ingot $\mathrm{Mn}_{0.85} \mathrm{Bi}_{2.1} \mathrm{Te}_{4}$ for thermoelectric characterization (Figure 5). The Seebeck coefficient, as well as electrical and thermal conductivities, shows a good cyclability, which suggests the absence of a pronounced phase transition or decomposition in the compacted ingot. This is supported by a PXRD pattern obtained from the sample after the measurement of its transport properties. The sample shows only slight decomposition into $\mathrm{Bi}_{2} \mathrm{Te}_{3}$ (about 13 wt \%) and $\mathrm{MnTe}_{2}$ (below $1 \mathrm{wt} \%$, i.e., almost below the detection limit) (Figure S15).

The negative value of the Seebeck coefficient shows electron-dominated charge transport. This is in contrast to structurally related compounds, like $\mathrm{GeBi}_{2} \mathrm{Te}_{4}$ and $\mathrm{SnBi}_{2} \mathrm{Te}_{4}$, for which the Seebeck coefficients of 102 and $64 \mu \mathrm{V} \mathrm{K}{ }^{-1}$, respectively, at room temperature have been reported. ${ }^{38}$ On the other hand, it is in line with $-59 \mu \mathrm{V} \mathrm{K} \mathrm{K}^{-1}$ at room temperature for $\mathrm{PbBi}_{2} \mathrm{Te}_{4}{ }^{38}$ The temperature dependence of the absolute value of the Seebeck coefficient for all of these compounds is negative, which is in good accordance with our experiments. The electrical conductivity $\sigma$ of our polycrystalline samples is about $475 \mathrm{~S} \mathrm{~cm}^{-1}$ at room temperature, in good agreement with the data on a single crystal in the previous section. The negative temperature dependence of $\sigma$, i.e., the metallic character, makes the compound stand out when compared to $\mathrm{GeBi}_{2} \mathrm{Te}_{4}$ and $\mathrm{SnBi}_{2} \mathrm{Te}_{4}$, which both show increasing electrical conductivity in this temperature range. $\mathrm{PbBi}_{2} \mathrm{Te}_{4}$, however, exhibits the same metallic characteristics as $\mathrm{MnBi}_{2} \mathrm{Te}_{4}$. The thermal conductivity is nearly temperature independent with only a slight negative trend with increasing temperature. Combined, the enhanced Seebeck coefficient and thermal conductivity overcompensate the lower electrical conductivity at a higher temperature, leading to a maximum $Z T$ value of 0.17 at $400{ }^{\circ} \mathrm{C}$.

\section{CONCLUSIONS}

We have developed synthetic routes for single crystals and powders of $\mathrm{MnBi}_{2} \mathrm{Te}_{4}$, which grant access to the experimental exploration of this candidate antiferromagnetic topological insulator. $\mathrm{MnBi}_{2} \mathrm{Te}_{4}$ is an attractive testbed for the realization of various quantum effects, originating from a crossover between the nontrivial topology of electronic structure and long-range magnetic ordering.

We identify the synthetic issues that had been limiting the experimental progress on bulk $\mathrm{MnBi}_{2} \mathrm{Te}_{4}$. This compound is thermodynamically stable in a narrow temperature window below its melting point of ca. $600{ }^{\circ} \mathrm{C}$ well above room temperature. Fortunately, $\mathrm{MnBi}_{2} \mathrm{Te}_{4}$ samples can be quenched to room temperature since the decomposition of synthesized single crystals and compact polycrystalline powders is kinetically hindered. Long-term heating outside the stability range leads to decomposition of powder samples, the decomposition rate likely depending on the grain size.

Our crystal-structure elucidation using single-crystal X-ray diffraction and electron microscopy reveals the ubiquity of antisite defects in both cation positions and hints at possible nonstoichiometry of the title compound, which could not be resolved from earlier powder diffraction data. Accounts of different groups on synthesis of bulk $\mathrm{MnBi}_{2} \mathrm{Te}_{4}$ by Bridgman method $^{32}$ and out of a $\mathrm{Bi}-\mathrm{Te}$ flux ${ }^{67}$ are emerging, but only Rietveld structure refinements are discussed.

Magnetization, specific heat, transport, spectroscopic, and thermoelectric measurements identify both single crystals and polycrystalline $\mathrm{MnBi}_{2} \mathrm{Te}_{4}$ and $\mathrm{Mn}_{0.85} \mathrm{Bi}_{2.1} \mathrm{Te}_{4}$ samples as n-type metallic conductors that undergo a transition into a $3 \mathrm{D}$ antiferromagnetically ordered phase at about $24 \mathrm{~K}$. A preliminary angle-resolved photoelectron spectroscopy study shows a surface state at the $\bar{\Gamma}$ point with a gapped Dirac-conelike dispersion, which strengthens $\mathrm{MnBi}_{2} \mathrm{Te}_{4}$ as a viable 
candidate for an antiferromagnetic topologically nontrivial material. The corresponding full study is reported elsewhere. ${ }^{32}$

Forthcoming endeavors aim at doping of $\mathrm{MnBi}_{2} \mathrm{Te}_{4}$ to optimize the position of the Fermi energy within the bulk gap. First-principles calculations foresee that stable compounds isostructural to $\mathrm{MnBi}_{2} \mathrm{Te}_{4}$ could exist in the $\mathrm{Mn}-\mathrm{Bi}-\mathrm{Se}$ and $\mathrm{Mn}-\mathrm{Sb}-\mathrm{Te}$ systems, ${ }^{22}$ thus substantiating the feasibility of doping or even expansion of this structure family toward new Mn-containing derivatives. First experimental accounts on $\mathrm{MnBi}_{2} \mathrm{Se}_{4}$ thin films produced as a capping layer ${ }^{55}$ or as a multilayer $\mathrm{MnBi}_{2} \mathrm{Se}_{4} / \mathrm{Bi}_{2} \mathrm{Se}_{3}$ heterostructure ${ }^{48}$ have appeared recently. The layered $\mathrm{MnBi}_{2} \mathrm{Te}_{4}$ material is thus envisioned as a progenitor of the new family of functional materials available both as bulk and thin films.

\section{EXPERIMENTAL SECTION}

Synthesis and Crystal Growth. $\mathrm{Bi}_{2} \mathrm{Te}_{3}$ and $\alpha$-MnTe were synthesized by annealing stoichiometric mixtures of the elements (bismuth, Merck, treated at $220{ }^{\circ} \mathrm{C}$ in $\mathrm{H}_{2}$-flow; tellurium, Merck, >99.9\%; manganese, Sigma-Aldrich, treated with $\mathrm{SiO}_{2}$ at $900{ }^{\circ} \mathrm{C}$ under vacuum). The starting materials were pulverized by ball-milling ("Pulverisette 23", Fritsch) for 25 min under an argon atmosphere in a glovebox. The homogeneous powder was pressed into pellets with a diameter of $6 \mathrm{~mm}$ with an applied pressure of $0.7 \mathrm{GPa}$ and sealed in an evacuated silica ampule. The binaries were used as precursors for crystal-growth experiments. For this purpose, the binary reactants were ground either manually or by ball-milling under an argon atmosphere in a glovebox and sealed in an evacuated silica ampule.

The choice of binary precursors was governed by the following considerations: (1) a better control of the Te stoichiometry with respect to the highly volatile elemental tellurium; (2) the structural similarity between the reactants and $\mathrm{MnBi}_{2} \mathrm{Te}_{4}$ may promote the solid-state reaction; (3) the probability of any reduction-oxidation reaction leading to the formation of $\mathrm{MnTe}_{2}$ and Bi-rich bismuth tellurides may decrease, since the oxidation states of the cations are the same in the reactants and in the product.

Since MnTe melts peritectically at $1151{ }^{\circ} \mathrm{C},{ }^{56}$ annealing of the elements at $950{ }^{\circ} \mathrm{C}$ for 1 day following ref 25 also does not ensure complete homogenization. Both approaches, from the elements and from the binaries, basically start a similar mixture of $\mathrm{Bi}_{2} \mathrm{Te}_{3}$ and $\mathrm{MnTe}$ on the stage of a long-term annealing at above $500{ }^{\circ} \mathrm{C}$.

The crystal size in our experiments was influenced by cooling rates within the Ostwald-Miers region and various annealing times at subsolidus temperatures. For small single crystals (up to $100 \mu \mathrm{m}$ ), a rate of $6 \mathrm{~K} \mathrm{~h}^{-1}$ was used with an annealing temperature of $590{ }^{\circ} \mathrm{C}$. Larger single crystals were grown with smaller cooling rates $\left(1 \mathrm{~K} \mathrm{~h}^{-1}\right)$ and longer annealing times at the same temperature.

Thermochemical Analysis. The samples were analyzed by means of differential scanning calorimetry (DSC) using a Setaram Labsys ATD-DSC device with a k-probe thermocouple $\left(\mathrm{Ni}-\mathrm{Cr} / \mathrm{Ni}-\mathrm{Al} ; \mathrm{T}_{\max }\right.$ $=800{ }^{\circ} \mathrm{C}$ ) and $\mathrm{Al}_{2} \mathrm{O}_{3}$ as a reference compound. Heating and cooling rates of $2 \mathrm{~K} \mathrm{~min}^{-1}$ were employed. Weighted amounts of the manually ground samples were sealed in small evacuated silica ampules and exposed to two consecutive heating-cooling cycles up to the chosen temperature.

X-ray Diffraction Experiments. Single-crystal X-ray diffraction data were collected on a four-circle Kappa APEX II CCD diffractometer (Bruker) with a graphite (002)-monochromator and a charge coupled device (CCD)-detector at $T=296(2) \mathrm{K}$. Mo K $\alpha$ radiation $(\lambda=71.073 \mathrm{pm})$ was used. A numerical absorption correction based on an optimized crystal description was applied, ${ }^{57}$ and the initial structure solution was performed in JANA2006. ${ }^{58}$ The structure was refined in SHELXL against $\left|F_{0}\right|^{2.59,60}$ Further details on the crystal-structure investigations of $\mathrm{Mn}_{0.85(3)} \mathrm{Bi}_{2.10(3)} \mathrm{Te}_{4}$ and $\mathrm{MnBi}_{2} \mathrm{Te}_{4}$ can be obtained from the Fachinformationszentrum Karlsruhe, 76344 Eggenstein-Leopoldshafen, Germany [fax, (+49)7247-808-666; E-mail, crysdata@fiz-karlsruhe.de], on quoting the depository numbers CSD-1876907 and CSD-1876906.
Powder X-ray diffraction data were measured using an X'Pert Pro diffractometer (PANalytical) with Bragg-Brentano geometry or a Huber G670 diffractometer with an integrated imaging plate detector and read-out system. Both machines operate with a curved $\mathrm{Ge}(111)$ monochromator and $\mathrm{Cu} \mathrm{K} \alpha_{1}$ radiation $(\lambda=154.06 \mathrm{pm})$. Variable divergence slits were used on the X'Pert Pro equipment to keep the illuminated sample area constant. Phase fractions in the powder samples have been estimated by Rietveld refinements of the data; the fundamental parameter approach was applied in the TOPAS package. ${ }^{61}$ The preferred orientation of the crystallites was described by spherical harmonics functions. The graphics of the structures were made with the Diamond software. ${ }^{62}$

Transmission Electron Microscopy. An FEI Helios NanoLab $600 \mathrm{i}$ focused ion beam system was used to cut a TEM-transparent lamella from a $\mathrm{MnBi}_{2} \mathrm{Te}_{4}$ single crystal. SAED patterns were acquired on a TEM FEI Tecnai G2 microscope (200 kV accelerating voltage, $\mathrm{LaB}_{6}$ filament). HR-STEM and EELS investigations have been performed using an FEI Titan3 80-300 double aberration-corrected microscope with a GATAN GIF Tridiem 865ER spectrometer, operated at $80 \mathrm{kV}$ accelerating voltage. The convergence semiangle of the electron beam was set to $21.5 \mathrm{mrad}$. Due to the weak Mn signal and strong contamination during the spectrum image acquisition, post data treatment using a principal component analysis was applied. ${ }^{63}$ Six main loadings have been used to reconstruct and denoise the spectrum image.

Energy-Dispersive X-ray Spectroscopy. Samples were prepared by embedding small crystals of $\mathrm{Bi}_{2} \mathrm{Te}_{3}, \mathrm{MnTe}$, and the title compound into a synthetic resin (versosit), subsequent polishing to ensure a flat surface, and thin carbon-coating to provide a conducting surface. EDX spectra were recorded with a high-resolution SEM EVOMA 15 (Zeiss) equipped with a Peltier-cooled $\mathrm{Si}(\mathrm{Li})$ detector (Oxford Instruments) employing $30 \mathrm{kV}$ acceleration voltage. Element quantification was obtained from least-square fitting of edge models (Mn-K, Te-L, Bi-L, and Bi-M) invoking $k$ factor calibration from the stoichiometric samples of similar composition $\left(\mathrm{Bi}_{2} \mathrm{Te}_{3}\right.$ and $\left.\mathrm{MnTe}\right)$. To assess systematic errors stemming from the different edge and reference choices, we included both $\mathrm{Bi}-\mathrm{L}$ and $\mathrm{M}$-edge as well as $\mathrm{Bi}_{2} \mathrm{Te}_{3}$ and $\mathrm{MnTe}$ references for $\mathrm{Te}$ in our quantification statistics.

Photoemission and X-ray Absorption Experiments. $\mathrm{MnBi}_{2} \mathrm{Te}_{4}(001)$ surfaces were prepared in situ in ultrahigh vacuum by cleaving single crystals using a metal post glued on top of the sample.

We performed ARPES experiments on $\mathrm{MnBi}_{2} \mathrm{Te}_{4}(001)$ at the Microscopic and Electronic Structure Observatory (MAESTRO) at beamline 7 of the Advanced Light Source (ALS). Measurements were performed in an ultrahigh vacuum of lower than $1 \times 10^{-10} \mathrm{mbar}$ for samples cooled down to approximately $18 \mathrm{~K}$. The total energy and momentum resolutions were ca. $20 \mathrm{meV}$ and ca. $0.01 \AA^{-1}$, respectively.

XPS and XAS measurements were performed at the ASPHERE III endstation at the Variable Polarization XUV Beamline P04 at PETRA III (DESY), providing a high photon flux over a wide range of photon energies $(h \nu=250-3000 \mathrm{eV})$. The energy resolution of the XPS measurements was approximately $100 \mathrm{meV}$.

We performed XLD experiments at the BOREAS beamline of the ALBA synchrotron light source using linearly polarized X-rays. The experiments were carried out at temperatures of $T=2$ and $40 \mathrm{~K}$ in the total electron yield (TEY) mode. Grazing and normal incidence measurement geometries were achieved by rotating the sample relative to the light beam.

Magnetic Characterization. Temperature- and field-dependent magnetic measurements were performed on a $\mathrm{MnBi}_{2} \mathrm{Te}_{4}$ melt ingot (ca. $58 \mathrm{mg}$ ) using a Superconducting Quantum Interference Device magnetometer (MPMS3) from Quantum Design, Inc.

Temperature-dependent zero field-cooled and field-cooled warming magnetization measurements were performed at a magnetic field of $1 \mathrm{~T}$ in the temperature range of $2-320 \mathrm{~K}$, and field-dependent magnetization measurements were done at temperatures of 2 and 300 $\mathrm{K}$. 
All samples were mounted with the glue Duosan on a silica glass holder, and the magnetization data were corrected by the magnetic moment of the glue. The Neel temperature was determined by $\partial(\chi$. $T) / \partial T$ according to Fisher. ${ }^{64}$ The critical field of the spin-flop transition was determined by the derivative of the magnetization with respect to the magnetic field.

Specific Heat. Specific heat measurements were performed on several single crystals (ca. $1.6 \mathrm{mg}$ in total) with a preferred orientation [plane (001) perpendicular to $H$ ] between 1.8 and $50 \mathrm{~K}$ using a heatpulse relaxation method in a Physical Properties Measurement System from Quantum Design. The heat capacity of the sample holder (addenda) was determined prior to the measurements to separate the heat capacity contribution of the sample from the total heat capacity. The transition temperature $T_{\mathrm{N}}$ was determined via an entropyconserving construction.

Resistivity Measurements. The in-plane electrical resistivity of a $\mathrm{MnBi}_{2} \mathrm{Te}_{4}$ single crystal was measured in a home-built setup utilizing a standard 4-point geometry in a liquid helium environment. Two cooling-heating cycles from room temperature to $4.5 \mathrm{~K}$ yielded reproducible resistivity data with no hysteresis, proving good chemical and mechanical stability of the sample and the contacts applied to its surface. The linear response was confirmed by varying the excitation current in the second cycle, resulting in an identical $\rho(T)$ curve. The electrical current density was assumed homogeneous across the single crystal's cross section. However, due to the layered structure, the current density might be increased close to the sample surface where the electrical field gradient is picked up, resulting in an overestimation of the resistivity. The absolute values of the electrical conductivity given in the Results and Discussion section should therefore be regarded as a lower limit only.

Thermoelectric Measurements. Thermal diffusivity measurements were performed under a $\mathrm{He}$ atmosphere with a Linseis LFA1000 apparatus equipped with an InSb detector. Simultaneous heat loss and finite pulse corrections were corrected using Dusza's model. ${ }^{65}$ The values were averaged over five measurement points at each temperature. The samples, polished to a uniform thickness of $1.88 \mathrm{~mm}$, were placed on an aperture of $3 \mathrm{~mm}$ diameter. For the $\kappa$ calculation, diffusivity values were multiplied with the Dulong-Petit heat capacity $\left(C_{\mathrm{p}}=0.1739 \mathrm{~J} \mathrm{~g}^{-1} \mathrm{~K}^{-1}\right)$ and the density as derived by the weight and the volume determined by Archimedes' principle ( $\rho=$ $7.409 \mathrm{~g} \mathrm{~cm}^{-3}$ ). For isostructural materials in the $\mathrm{Ge}-\mathrm{Sb}-\mathrm{Te}$ system, the Dulong-Petit approximation yielded $C_{\mathrm{p}}$ values close to the measured ones. ${ }^{66}$ The Seebeck coefficient $S$ and the electrical conductivity $\sigma$ were measured simultaneously under a He atmosphere with a Linseis LSR-3 instrument with $\mathrm{NiCr} / \mathrm{Ni}$ and $\mathrm{Ni}$ contacts and a continuous reverse of the polarity of the thermocouples (bipolar setup). Specimens were cut from the ingots along different directions with dimensions of $7 \mathrm{~mm} \times 2 \mathrm{~mm} \times 2 \mathrm{~mm}$. The errors of $S$ and $\sigma$ are smaller than $10 \%$; for $\kappa$, they are ca. $5 \%$. As a result, the $Z T$ values given may exhibit an absolute uncertainty of up to $20 \%$.

\section{ASSOCIATED CONTENT}

\section{S Supporting Information}

The Supporting Information is available free of charge on the ACS Publications website at DOI: 10.1021/acs.chemmater.8b05017.

Powder synthesis of $\mathrm{MnBi}_{2} \mathrm{Te}_{4}$; thermal stability of $\mathrm{MnBi}_{2} \mathrm{Te}_{4} ;$ crystal-structure elucidation of the nonstoichiometric $\mathrm{Mn}_{0.85(3)} \mathrm{Bi}_{2.10(3)} \mathrm{Te}_{4}$ model; crystal-structure elucidation of the stoichiometric $\mathrm{MnBi}_{2} \mathrm{Te}_{4}$ model; thermoelectric characterization of $\mathrm{Mn}_{0.85} \mathrm{Bi}_{2.1} \mathrm{Te}_{4}$ (PDF)

\section{AUTHOR INFORMATION}

\section{Corresponding Author}

*E-mail: anna.isaeva@tu-dresden.de.

ORCID

Oliver Oeckler: 0000-0003-0149-7066
Thomas Doert: 0000-0001-7523-9313

Michael Ruck: 0000-0002-2391-6025

Anna Isaeva: 0000-0001-6590-1393

\section{Author Contributions}

The manuscript was written through contributions of all authors. All authors have given approval to the final version of the manuscript.

Notes

The authors declare no competing financial interest.

\section{ACKNOWLEDGMENTS}

We gratefully acknowledge experimental support by the beamline staff at the beamlines BOREAS (Alba), MAESTRO (ALS), and P04 (PETRA III). We thank G. Kreutzer (LeibnizInstitute for Solid State and Materials Research, Dresden) for the EDX measurements. This work was supported by the German Research Foundation (DFG) in the framework of the Special Priority Program (SPP 1666, IS 250/2-1) “Topological Insulators" and project OE $530 / 5-1$, by the ERA-Chemistry Program (RU 766/15-1), by CRC "Correlated Magnetism: From Frustration to Topology" (SFB 1143), and by CRC "Tocotronics" (SFB 1170).

\section{ABBREVIATIONS}

TI, topological insulator; DSC, differential scanning calorimetry; PXRD, powder X-ray diffraction; SCXRD, single-crystal $\mathrm{X}$-ray diffraction; SEM, scanning electron microscopy; TEM, transmission electron microscopy; ED, electron diffraction; HRTEM, high-resolution transmission electron microscopy

\section{REFERENCES}

(1) Hasan, M. Z.; Kane, C. L. Colloquium: Topological insulators. Rev. Mod. Phys. 2010, 82, 3045.

(2) Haldane, F. D. M. Model for a quantum Hall effect without Landau levels: Condensed-matter realization of the "parity anomaly". Phys. Rev. Lett. 1988, 61, No. 2015.

(3) Yu, R.; Zhang, W.; Zhang, H.-J.; Zhang, S.-C.; Dai, X.; Fang, Z. Quantized anomalous Hall effect in magnetic topological insulators. Science 2010, 329, 61-64.

(4) Essin, A. M.; Moore, J. E.; Vanderbilt, D. Magnetoelectric polarizability and axion electrodynamics in crystalline insulators. Phys. Rev. Lett. 2009, 102, No. 146805.

(5) Weng, H.; Yu, R.; Hu, X.; Dai, X.; Fang, Z. Quantum anomalous Hall effect and related topological electronic states. Adv. Phys. 2015, 64, 227-282.

(6) Chang, C.-Z.; Zhang, J.; Feng, X.; Shen, J.; Zhang, Z.; Guo, M.; Li, K.; Ou, Y.; Wei, P.; Wang, L.-L.; Ji, Z.-Q.; Feng, Y.; Ji, S.; Chen, X.; Jia, J.-F.; Dai, X.; Fang, Z.; Zhang, S.-C.; He, K.; Wang, Y.; Lu, L.; Ma, X.-C.; Xue, Q.-K. Experimental observation of the quantum anomalous Hall effect in a magnetic topological insulator. Science 2013, 340, 167-170.

(7) Chang, C.-Z.; Zhao, W.; Kim, D. Y.; Zhang, H.; Assaf, B. A.; Heiman, D.; Zhang, S.-C.; Liu, C.; Chan, M. H. W.; Moodera, J. S. High-precision realization of robust quantum anomalous Hall state in a hard ferromagnetic topological insulator. Nat. Mater. 2015, 14, 473-477.

(8) Kou, X.; He, L.; Lang, M.; Fan, Y.; Wong, K.; Jiang, Y.; Nie, T.; Jiang, W.; Upadhyaya, P.; Xing, Z.; Wang, Y.; Xiu, F.; Schwartz, R. N.; Wang, K. L. Manipulating surface-related ferromagnetism in modulated-doped topological insulators. Nano Lett. 2013, 13, 4587-4593.

(9) Yoshimi, R.; Yasuda, K.; Tsukazaki, A.; Takahashi, K. S.; Nagaosa, N.; Kawasaki, M.; Tokura, Y. Quantum Hall states stabilized in semi-magnetic bilayers of topological insulators. Nat. Commun. 2015, 6, No. 8530 
(10) Mogi, M.; Yoshimi, R.; Tsukazaki, A.; Yasuda, K.; Kozuka, Y.; Takahashi, K. S.; Kawasaki, M.; Tokura, Y. Magnetic modulation doping in topological insulators toward higher-temperature quantum anomalous Hall effect. Appl. Phys. Lett. 2015, 107, No. 182401.

(11) Luo, W.; Qi, X.-L. Massive Dirac surface states in topological insulator/magnetic insulator heterostructures. Phys. Rev. B 2013, 87, No. 085431 .

(12) Lee, C.; Katmis, F.; Jarillo-Herrero, P.; Moodera, J. S.; Gedik, $\mathrm{N}$. Direct measurement of proximity-induced magnetism at the interface between a topological insulator and a ferromagnet. Nat. Commun. 2016, 7, No. 12014.

(13) Katmis, F.; Lauter, V.; Nogueira, F. S.; Assaf, B. A.; Jamer, M. E.; Wei, P.; Satpati, B.; Freeland, J. W.; Eremin, I.; Heiman, D.; JarilloHerrero, P.; Moodera, J. S. A high-temperature ferromagnetic topological insulating phase by proximity coupling. Nature 2016, $533,513-516$.

(14) Jiang, Z.; Chang, C.-Z.; Tang, C.; Wei, P.; Moodera, J. S.; Shi, J. Independent tuning of electronic properties and induced ferromagnetism in topological insulators with heterostructure approach. Nano Lett. 2015, 15, 5835-5840.

(15) He, Q. L.; Kou, X.; Grutter, A. J.; Yin, G.; Pan, L.; Che, X.; Liu, Y.; Nie, T.; Zhang, B.; Disseler, S. M.; Kirby, B. J.; Ratcliff, W., II; Shao, Q.; Murata, K.; Zhu, X.; Yu, G.; Fan, Y.; Montazeri, M.; Han, X.-D.; Borchers, J. A.; Wang, K. L. Tailoring exchange couplings in magnetic topological-insulator/antiferromagnet heterostructures. Nat. Mater. 2017, 16, 94-100.

(16) Tang, C.; Chang, C.-Z.; Zhao, G.; Liu, Y.; Jiang, Z.; Liu, C.-X.; McCartney, M. R.; Smith, D. J.; Chen, T.; Moodera, J. S.; Shi, J. Above $400-\mathrm{K}$ robust perpendicular ferromagnetic phase in a topological insulator. Sci. Adv. 2017, 3, No. e1700307.

(17) Menshov, V. N.; Tugushev, V. V.; Eremeev, S. V.; Echenique, P. M.; Chulkov, E. V. Magnetic proximity effect in the threedimensional topological insulator/ferromagnetic insulator heterostructure. Phys. Rev. B 2013, 88, No. 224401.

(18) Eremeev, S. V.; Menshov, V. N.; Tugushev, V. V.; Echenique, P. M.; Chulkov, E. V. Magnetic proximity effect at the threedimensional topological insulator/magnetic insulator interfacr. Phys. Rev. B 2013, 88, No. 144430.

(19) Otrokov, M. M.; Menshchikova, T. V.; Rusinov, I. P.; Vergniory, M. G.; Kuznetsov, V. M.; Chulkov, E. V. Magnetic extension as an efficient method for realizing the quantum anomalous Hall state in topological insulators. JETP Lett. 2017, 105, 297.

(20) Otrokov, M. M.; Menshchikova, T. V.; Vergniory, M. G.; Rusinov, I. P.; Vyazovskaya, A. Y.; Koroteev, Y. M.; Bihlmayer, G.; Ernst, A.; Echenique, P. M.; Arnau, A.; Chulkov, E. V. Highly-ordered wide bandgap materials for quantized anomalous Hall and magnetoelectric effects. 2D Mater. 2017, 4, No. 025082.

(21) Henk, J.; Flieger, M.; Maznichenko, I. V.; Mertig, I.; Ernst, A.; Eremeev, S. V.; Chulkov, E. V. Topological character and magnetism of the Dirac state in Mn-doped $\mathrm{Bi}_{2} \mathrm{Te}_{3}$. Phys. Rev. Lett. 2012, 109, No. 076801.

(22) Eremeev, S. V.; Otrokov, M. M.; Chulkov, E. V. Competing rhombohedral and monoclinic crystal structures in $\mathrm{MnPn}_{2} \mathrm{Ch}_{4}$ compounds: an ab-initio study. J. Alloys Compd. 2017, 709, 172-178.

(23) Li, J.; Li, Y.; Du, S.; Wang, S.; Gu, B.-L.; Zhang, S.-C.; He, K.; Duan, W.; Xu, Y. Intrinsic magnetic topological insulators in van der Waals layered $\mathrm{MnBi}_{2} \mathrm{Te}_{4}$ family materials 2018, arXiv:1808.08608. arXiv.org e-Print archive. https://arxiv.org/abs/1808.08608 (accessed March 19, 2019).

(24) Zhang, D.; Shi, M.; Xing, D.; Zhang, H.; Wang, J. Topological axion states in magnetic insulator $\mathrm{MnBi}_{2} \mathrm{Te}_{4}$ with the quantized magnetoelectric effect 2018, arXiv:1808.08014. arXiv.org e-Print archive. https://arxiv.org/abs/1808.08014 (accessed March 19, 2019).

(25) Lee, D.-S.; Kim, T.-H.; Park, C.-H.; Chung, C.-Y.; Lim, Y. S.; Seo, W.-S.; Park, H.-H. Crystal structure, properties and nanostructuring of a new layered chalcogenide semiconductor, $\mathrm{Bi}_{2} \mathrm{MnTe}_{4}$. Cryst. Eng. Commun. 2013, 15, 5532-5538.
(26) von Goldbeck, O. K. Iron-Binary Phase Diagrams; Springer: Berlin, 1982; Vol. 22.

(27) Teppo, O.; Niemelä, J.; Taskinen, P. Bi-Cu. Thermochim. Acta 1990, 173, 137-150.

(28) Nishizawa, T.; Ishida, K. The Co (cobalt) system. Bull. Alloy Phase Diagrams 1983, 4, 387-390.

(29) Yang, J. B.; Kamaraju, K.; Yelon, W. B.; James, W. J.; Cai, Q.; Bollero, A. Magnetic properties of the $\mathrm{MnBi}$ intermetallic compound. Appl. Phys. Lett. 2001, 79, 1846.

(30) Walsh, J. P. S.; Freedman, D. E. High-pressure synthesis: A new frontier in the search for next-generation intermetallic compounds. Acc. Chem. Res. 2018, 51, 1315-1323.

(31) Schwarz, U.; Tencé, S.; Janson, O.; Koz, C.; Krellner, C.; Burkhardt, U.; Rosner, H.; Steglich, F.; Grin, Y. $\mathrm{CoBi}_{3}$ : a binary cobalt-bismuth compound and superconductor. Angew. Chem., Int. Ed. 2013, 52, 9853-9857.

(32) Otrokov, M. M.; Klimovskikh, I. I.; Bentmann, H.; Zeugner, A.; Aliev, Z. S.; Gaß, S.; Wolter, A. U. B.; Koroleva, A. V.; Estyunin, D.; Shikin, A. M.; BlancoRey, M.; Hoffmann, M.; Vyazovskaya, A. Y.; Eremeev, S. V.; Koroteev, Y. M.; Amiraslanov, I. R.; Babanly, M. B.; Mamedov, N. T.; Abdullayev, N. A.; Zverev, V. N.; Büchner, B.; Schwier, E. F.; Kumar, S.; Kimura, A.; Petaccia, L.; Di Santo, G.; Vidal, R. C.; Schatz, S.; Kiner, K.; Min, C.-H.; Moser, S. K.; Peixoto, T. R. F.; Reinert, F.; Ernst, A.; Echenique, P. M.; Isaeva, A.; Chulkov, E. V. Prediction and observation of the first antiferromagnetic topological insulator 2018, arXiv:1809.07389. arXiv.org e-Print archive. https://arxiv.org/abs/1809.07389 (accessed March 19, 2019).

(33) Mong, R. S. K.; Essin, A. M.; Moore, J. E. Antiferromagnetic topological insulators. Phys. Rev. B 2010, 81, No. 245209.

(34) Gong, Y.; Guo, J.; Li, J.; Zhu, V.; Liao, M.; Liu, X.; Zhang, Q.; Gu, L.; Tang, L.; Feng, X.; Zhang, D.; Li, W.; Song, C.; Wang, L.; Yu, P.; Chen, X.; Wang, Y.; Yao, H.; Duan, W.; Xu, Y.; Zhang, S.-C.; Ma, X.; Xue, Q.-K.; He, K. Experimental realization of an intrinsic magnetic topological insulator 2018, 1809.07926. arXiv.org. https:// arxiv.org/abs/1809.07926 (accessed March 19, 2019).

(35) Peng, Y.; Xu, Y. Proximity-induced Majorana hinge modes in antiferromagnetic topological insulators. 2018, arXiv:1809.09112v2. arXiv.org e-Print archive. https://arxiv.org/abs/1809.09112v2 (accessed March 19, 2019).

(36) Armitage, N. P.; Wu, L. On the matter of topological insulators as magnetoelectrics 2018, arXiv:1810.01233v2. arXiv.org e-Print archive. https://arxiv.org/abs/1810.01233v2 (accessed March 19, 2019).

(37) Furberg, S.; et al. On the system manganese-tellurium. Acta Chem. Scand. 1953, 7, 693-694.

(38) Kuznetsov, V. L.; Kuznetsova, L. A.; Rowe, D. M. Thermoelectric properties and crystal structures of ternary compounds in the $\mathrm{Ge}(\mathrm{Sn}, \mathrm{Pb}) \mathrm{Te}-\mathrm{Bi}_{2} \mathrm{Te}_{3}$ systems. J. Phys. Chem. Solids 2000, 61, 12691274.

(39) Welzmiller, S.; Schlegel, R.; Pöppl, A.; Bothmann, G.; Scheidt, E.-W.; Scherer, W.; Oeckler, O. Doping $\mathrm{GeSb}_{2} \mathrm{Te}_{4}$ with $\mathrm{Cr}^{3+}$ : structure and temperature-dependent physical properties. Z. Anorg. Allg. Chem. 2015, 641, 2350-2356.

(40) Karpinskii, O. G.; Shelimova, L. E.; Kretova, M. A. Crystal structure and point defects of $\mathrm{Ge}_{1+\delta} \mathrm{Bi}_{2} \mathrm{Te}_{4}$. Inorg. Mater. 1997, 33, 793-797.

(41) Schneider, M. N.; Oeckler, O. Unusual solid solutions in the system Ge-Sb-Te: The crystal structure of $33 \mathrm{R}-\mathrm{Ge}_{4-\mathrm{x}} \mathrm{Sb}_{2-\mathrm{y}} \mathrm{Te}_{7}(\mathrm{x}, \mathrm{y}=$ 0.1 ) is isostructural to that of $\mathrm{Ge}_{3} \mathrm{Sb}_{2} \mathrm{Te}_{6}$. Z. Anorg. Allg. Chem. 2008, $634,2557-2561$.

(42) Lee, S.; Fischer, E.; Czerniak, J.; Nagasundaram, N. Synthesis and structure of two phases with both extended and point defects: $\mathrm{Mn}_{1-\mathrm{x}} \mathrm{Bi}_{2+\mathrm{y}} \mathrm{S}_{4}$ and $\mathrm{Mn}_{1-\mathrm{x}} \mathrm{Bi}_{2+\mathrm{y}} \mathrm{Se}_{4}$. J. Alloys Compd. 1993, 197, 1-5.

(43) Kurowski, D. Mangan-Chalkogenometallate der 15. Gruppe und binäre Kupfertelluride - Synthese, Strukturen, Hochdruckchemie und physikalische Eigenschaften. PhD. Thesis, University of Regensburg, 2003. 
(44) Ranmohotti, K. G. S.; Djieutedjeu, H.; Poudeu, P. F. P. Chemical manipulation of magnetic ordering in $\mathrm{Mn}_{1-\mathrm{x}} \mathrm{Sn}_{\mathrm{x}} \mathrm{Bi}_{2} \mathrm{Se}_{4}$ solidsolutions. J. Am. Chem. Soc. 2012, 134, 14033-14042.

(45) Shevelkov, A. V.; Dikarev, E. V.; Shpanchenko, R. V.; Popovkin, B. A. Crystal structures of bismuth tellurohalides BiTeX (X $=\mathrm{Cl}, \mathrm{Br}$, I) from X-ray powder diffraction data. J. Solid State Chem. 1995, 114, $379-384$

(46) Zeugner, A.; Kaiser, M.; Schmidt, P.; Menshchikova, T. V.; Rusinov, I. P.; Markelov, A. V.; Van den Broek, W.; Chulkov, E. V.; Isaeva, A.; et al. Modular design of $2 \mathrm{D}$ topological-insulator building blocks: optimized synthesis and crystal growth and crystal and electronic structures of $\mathrm{Bi}_{\mathrm{x}} \mathrm{TeI}(\mathrm{x}=2,3)$. Chem. Mater. 2017, 29, 1321-1337.

(47) Zeugner, A.; Teichert, J.; Kaiser, M.; Menshchikova, T. V.; Rusinov, I. P.; Markelov, A. V.; Chulkov, E. V.; Doert, T.; Ruck, M.; Isaeva, A. Synthesis, crystal and topological electronic structures of new bismuth tellurohalides $\mathrm{Bi}_{2} \mathrm{TeBr}$ and $\mathrm{Bi}_{3} \mathrm{TeBr}$. Chem. Mater. 2018, $30,5272-5284$.

(48) The origin of the different $\chi_{0}$ for the polycrystalline melt ingot $\left(\chi_{0}=-1.9 \times 10^{-4} \mathrm{emu} \mathrm{mol}^{-1} \mathrm{Oe}\right)$ compared to the results on our single crystals ${ }^{32}$ is not fully understood and will be elucidated in the future.

(49) Hess, C.; Kondrat, A.; Narduzzo, A.; Hamann-Borrero, J. E.; Klingeler, R.; Werner, J.; Behr, G.; Büchner, B. The intrinsic electronic phase diagram of iron-oxypnictide superconductors. Europhys. Lett. 2009, 87, No. 17005.

(50) Qiao, R.; Chin, T.; Harris, S. J.; Yan, S.; Yang, W. Spectroscopic fingerprints of valence and spin states in manganese oxides and fluorides. Curr. Appl. Phys. 2013, 13, 544-548.

(51) Kurata, H.; Colliex, C. Electron-energy-loss core-edge structures in manganese oxides. Phys. Rev. B 1993, 48, No. 2102.

(52) Sangaletti, L.; Pagliara, S.; Dimitri, I.; Parmigiani, I. D. F.; Goldoni, A.; Floreano, L.; Morgante, A.; Aguekian, V. F. Electronic properties of the $\mathrm{Mn}-\mathrm{CdTe}(110)$ interface probed by resonant photoemission at the Mn 2p-3d absorption threshold. Surf. Sci. 2004, 566-568, 508-514.

(53) Hagmann, J. A.; Li, X.; Chowdhury, S.; Dong, S.-N.; Rouvimov, S.; Pookpanratana, S. J.; Yu, K. M.; Orlova, T. A.; Bolin, T. B.; Segre, C. U.; Seiler, D. G.; Richter, C. A.; Liu, X.; Dobrowolska, M.; Furdyna, J. K. Molecular beam epitaxy growth and structure of selfassembled $\mathrm{Bi}_{2} \mathrm{Se}_{3} / \mathrm{Bi}_{2} \mathrm{MnSe}_{4}$ multilayer heterostructures. New J. Phys. 2017, 19, No. 085002.

(54) Biesinger, M. C.; Payne, B. P.; Grosvenor, A. P.; Lau, L. W. M.; Gerson, A. R.; Smart, R. S. C. Resolving surface chemical states in XPS analysis of first row transition metals, oxides and hydroxides: $\mathrm{Cr}$, $\mathrm{Mn}, \mathrm{Fe}, \mathrm{Co}$ and Ni. Appl. Surf. Sci. 2011, 257, 2717-2730.

(55) Hirahara, T.; Eremeev, S. V.; Shirasawa, T.; Okuyama, Y.; Kubo, T.; Nakanishi, R.; Akiyama, R.; Takayama, A.; Hajiri, T.; Ideta, S.-I.; Matsunami, M.; Sumida, K.; Miyamoto, K.; Takagi, Y.; Tanaka, K.; Okuda, T.; Yokoyama, T.; Kimura, S.-I.; Hasegawa, S.; Chulkov, E. V. Large-gap magnetic topological heterostructure formed by subsurface incorporation of a ferromagnetic layer. Nano Lett. 2017, 17, 3493-3500.

(56) Lasocka, M. Binary Alloy Phase Diagrams; Massalski, T. B., Ed.; ASM International: Materials Park, OH, 1990; Vol. 3, p 2609.

(57) X-Shape, Crystal Optimization for Numerical Absorption Correction Program, v. 2.12.2; Stoe \& Cie GmbH: Darmstadt, 2009.

(58) Petricek, V.; Dusek, M.; Palatinus, L. JANA2006, The Crystallographic Computing System; Institute of Physics: Praha, Czech Republic, 2011.

(59) Sheldrick, G. M. A short history of SHELX. Acta Crystallogr., Sect. A: Found. Crystallogr. 2008, 64, 112-122.

(60) Sheldrick, G. M. Crystal structure refinement with SHELXL. Acta Crystallogr., Sect. C: Struct. Chem. 2015, 71, 3-8.

(61) Coelho, A. TOPAS-Academic, v. 5, Brisbane, Australia, 2012.

(62) Brandenburg, K. Diamond 3.2k; Crystal Impact GbR: Bonn, 2014.

(63) Potapov, P. temDM-Software for TEM in DigitalMicrograph. www.temdm.com/web/ (accessed March 19, 2019).
(64) Fisher, M. E. Relation between the specific heat and susceptibility of an antiferromagnet. Philos. Mag. 1962, 7, 1731-1734.

(65) Dusza, L. Combined solution of the simultaneous heat loss and finite pulse corrections with the laser flash method. HTHP Abstr. 1995, 27, 467-473.

(66) Rosenthal, T.; Schneider, M. N.; Stiewe, C.; Döblinger, M.; Oeckler, O. Real structure and thermoelectric properties of GeTe-rich germanium antimony tellurides. Chem. Mater. 2011, 23, 4349-4356.

(67) Yan, J.-Q.; Zhang, Q.; Heitmann, T.; Huang, Z. L.; Wu, W. D.; Vaknin, D.; Sales, B. C.; McQueeney, R. J. Crystal growth and magnetic structure of $\mathrm{MnBi}_{2} \mathrm{Te}_{4}$ 2019, arXiv:1902.10110v2. arXiv.org e-Print archive. https://arxiv.org/abs/1902.10110v2 (accessed March 19, 2019). 